\title{
Presynaptic establishment of the synaptic cleft extracellular matrix is required for post-synaptic differentiation
}

\author{
Jeffrey Rohrbough, Emma Rushton, Elvin Woodruff III, Tim Fergestad, Krishanthan Vigneswaran, \\ and Kendal Broadie ${ }^{1}$
}

Department of Biological Sciences, Kennedy Center for Research on Human Development, Vanderbilt University, Nashville, Tennessee 37235, USA

\begin{abstract}
Formation and regulation of excitatory glutamatergic synapses is essential for shaping neural circuits throughout development. In a Drosophila genetic screen for synaptogenesis mutants, we identified mind the gap (mtg), which encodes a secreted, extracellular N-glycosaminoglycan-binding protein. MTG is expressed neuronally and detected in the synaptic cleft, and is required to form the specialized transsynaptic matrix that links the presynaptic active zone with the post-synaptic glutamate receptor (GluR) domain. Null mtg embryonic mutant synapses exhibit greatly reduced GluR function, and a corresponding loss of localized GluR domains. All known post-synaptic signaling/scaffold proteins functioning upstream of GluR localization are also grossly reduced or mislocalized in mtg mutants, including the dPix-dPak-Dock cascade and the Dlg/PSD-95 scaffold. Ubiquitous or neuronally targeted mtg RNA interference (RNAi) similarly reduce post-synaptic assembly, whereas post-synaptically targeted RNAi has no effect, indicating that presynaptic MTG induces and maintains the post-synaptic pathways driving GluR domain formation. These findings suggest that MTG is secreted from the presynaptic terminal to shape the extracellular synaptic cleft domain, and that the cleft domain functions to mediate transsynaptic signals required for post-synaptic development.
\end{abstract}

[Keywords: Glutamatergic synaptogenesis; post-synaptic density; glutamate receptor; secretion; Drosophila; neuromuscular junction]

Supplemental material is available at http://www.genesdev.org.

Received May 21, 2007; revised version accepted August 27, 2007.

Glutamatergic synapse formation and maturation is critical for sculpting neural circuits. Synaptogenesis defects cause crippling neurological disabilities ranging from motor ataxias to profound mental retardation, and subsequent modulation of glutamatergic synapses is a lifelong dynamic process underlying the ability to learn and remember (Kim and Sheng 2004; Malenka and Bear 2004; Perez-Otano and Ehlers 2005). A critical hypothesis, developed largely from the vertebrate neuromuscular junction (NMJ) model (Sanes and Lichtman 2001), is that presynaptic signals trigger post-synaptic assembly and modulation. Proposed secreted signals include Agrin (Sanes and Lichtman 2001; Bezakova and Ruegg 2003; Misgeld et al. 2005), WNTs (Hall et al. 2000; Packard et al. 2002; Salinas 2003), FGFs (Umemori et al. 2004), and Narp (O'Brien et al. 1999, 2002; Mi et al. 2002, 2004).

${ }^{1}$ Corresponding author.

E-MAIL kendal.broadie@vanderbilt.edu; FAX (615) 936-0129.

Article published online ahead of print. Article and publication date are online at http://www.genesdev.org/cgi/doi/10.1101/gad.1574107.
Transmembrane synaptic signaling proteins include SynCAM (Biederer et al. 2002; Sara et al. 2005), EphrinBEphB (Bruckner et al. 1999; Dalva et al. 2000), and $\beta$-neurexin/neuroligin (Scheiffele et al. 2000; Dean et al. 2003; Scheiffele 2003; Graf et al. 2004; Chih et al. 2005; Levinson et al. 2005; Nam and Chen 2005; Sara et al. 2005). Both classes of signals are proposed to interact intimately with a specialized synaptic cleft extracellular matrix (ECM), which is molecularly distinct from nonsynaptic ECM (Dityatev and Schachner 2003; Martin 2003b; Nishimune et al. 2004; Dityatev and Schachner 2006).

Synaptic cleft ECM components include heterotrimeric $(\alpha / \beta / \gamma)$ laminin glycoproteins (Nishimune et al. 2004) and heparan sulfate proteoglycans (HSPGs), which bind extracellular glucuronic acid and $\mathrm{N}$-acetyl glucosamine (GlcNAc) polysaccharides (Johnson et al. 2006; Viapiano and Matthews 2006). The secreted HSPGs Agrin and Perlecan are established regulators of NMJ synaptogenesis (Sanes and Lichtman 2001; Bezakova and 
Ruegg 2003; Kummer et al. 2004, 2006; Misgeld et al. 2005). The HSPG Syndecan (Sdc)-2 is similarly implicated in hippocampal synapse formation and plasticity (Ethell and Yamaguchi 1999; Ethell et al. 2001; Ethell and Pasquale 2005). ECM signaling at the mammalian NMJ also acts via the $\alpha / \beta$-dystroglycan-glycoprotein complex (DGC) (Henry and Campbell 1996; Grady et al. 2000). Numerous integrin receptors localize to mammalian NMJs and central glutamatergic synapses, and integrin-ECM interactions regulate aspects of synaptic development and modulation, including glutamatergic transmission and plasticity (Bahr et al. 1997; Staubli et al. 1998; Bahr 2000; Chavis and Westbrook 2001; Chan et al. 2003, 2006; Kramar et al. 2003, 2006; Lin et al. 2003; Bernard-Trifilo et al. 2005; Shi and Ethell 2006; Webb et al. 2006, 2007).

The Drosophila glutamatergic NMJ contains an ultrastructurally distinctive synaptic cleft ECM present only between pre- and post-synaptic densities (Prokop 1999), but little is known of its molecular composition. HSPGs, including laminin-binding Sdc (Fox and Zinn 2005; Johnson et al. 2006) and GPI-anchored Dallylike (Dlp) (Johnson et al. 2006), and the secreted Hikaru Genki (HIG) (Hoshino et al. 1996, 1999) are localized to the cleft ECM and regulate synaptic differentiation. A post-synaptic Dystrophin scaffold has recently been shown to regulate NMJ maturation (van der Plas et al. 2006). Drosophila WNT Wingless $(\mathrm{Wg})$ is a secreted anterograde synaptic maturation signal that acts via its pre/post-synaptic receptor Frizzled (Dfz2) (Packard et al. 2002; Marques 2005; Mathew et al. 2005; Ataman et al. 2006). Integrin ECM receptors and laminin are localized to NMJ synapses and regulate synapse formation, and both structural and functional development (Prokop et al. 1998; Beumer et al. 1999, 2002; Rohrbough et al. 2000; Hakeda-Suzuki et al. 2002).

The Drosophila NMJ post-synaptic domain contains two subclasses of tetrameric AMPA/kainate-like glutamate receptors (GluRs), composed of either IIA (A-class) or IIB (B-class) subunits, in combination with common required IIC, IID, and IIE subunits (Petersen et al. 1997; DiAntonio et al. 1999; Marrus and DiAntonio 2004; Marrus et al. 2004; Featherstone et al. 2005; Qin et al. 2005). The PDZ-domain scaffold Discs Large (Dlg), a PSD-95/ SAP70 homolog (Lahey et al. 1994), plays a key role in localizing post-synaptic proteins (Ashley et al. 2005; Gorczyca et al. 2007) including B-class GluRs (Chen and Featherstone 2005). The Drosophila p21-activated kinase (dPak), a serine threonine kinase activated by GTPases Rac and Cdc42 (Harden et al. 1996; Newsome et al. 2000; Mentzel and Raabe 2005), and its localizing Rhotype GEF, dPix (Werner and Manseau 1997; Hakeda-Suzuki et al. 2002), also play essential roles in the postsynaptic domain. dPAK interacts directly via its kinase domain with Dlg, and is required for Dlg synaptic expression (Parnas et al. 2001; Albin and Davis 2004). In a second pathway, dPak binding to the adaptor Dreadlocks (Dock) (Albin and Davis 2004), a Src homology (SH3 and SH2)-containing Nck homolog (Rao and Zipursky 1998; Ang et al. 2003; Rao 2005), regulates A-class GluR abun- dance (Albin and Davis 2004). The dPix-dPak-Dock and dPak-Dlg pathways therefore converge to regulate localization of both GluR classes in the post-synaptic domain.

Extensive work in this model system has established that the presynaptic neuron induces post-synaptic differentiation, inducing development and modulation of GluR domains (Broadie and Bate 1993a,b,c; Saitoe et al. 1997, 2001; Featherstone et al. 2002; Sigrist et al. 2003; Chen and Featherstone 2005). GluR domain formation involves lateral membrane receptor diffusion, receptor sequestration/anchoring mechanisms, regulated GluR subunit transcription, and local post-synaptic translation (Broadie and Bate 1993b; Sigrist et al. 2000, 2003; Chen et al. 2005; Rasse et al. 2005). To define the molecular mechanisms regulating functional post-synaptic differentiation, we undertook a systematic mutagenesis screen to isolate mutants with defective post-synaptic assembly. This approach has revealed mind the gap $(m t g)$, which encodes a secreted protein required for the formation of the synaptic cleft matrix, as well as a localization of the signaling pathways regulating GluR domains. Presynaptic $m t g$ knockdown inhibits post-synaptic differentiation, indicating that presynaptically secreted MTG organizes the extracellular cleft domain and is critically required for transsynaptic signaling that induces post-synaptic differentiation.

\section{Results}

\section{Isolation and mapping of mind the gap (mtg) mutants}

The mind the gap ( $\mathrm{mtg})$ mutation was isolated from a screen of $>6000$ lines for mutants with severely disrupted functional differentiation at the glutamatergic NMJ. EMS-mutagenized lines carrying the rucuca third chromosome markers ( $r u, h, t h, s t, c u, s r, e, c a)$ (Fig. 1A) were sequentially screened for mature embryonic/early larval lethality, normal gross anatomy and neuromuscular architecture, paralysis/reduced movement, and lastly, impaired neurotransmission at the embryonic NMJ. Mature $\mathrm{mtg}^{1}$ mutant embryos (21-22 h) are completely paralyzed, exhibiting no spontaneous or touchevoked movement, and $100 \%$ failure to hatch. Mutant embryos have normal body anatomy, and morphologically normal nervous system, musculature and NMJs. Manually hatched $\mathrm{mtg}^{1}$ embryos display weakened cuticle, and phenotypic posterior gut herniation; a few briefly display only slight, uncoordinated movement in saline, but no indication of neurally induced body wall peristalsis. All mtg mutants show severely compromised NMJ function (see below), indicating that $m t g$ is an essential gene required for glutamatergic synapse formation and function.

The $m t g$ locus was mapped by recombination onto a wild-type $(O R-R)$ chromosome, followed by complementation mapping with a defined set of genomic deficiencies (Fig. 1A). The smallest noncomplementing deficiency is $D f(3 R) C A 3$ (84F2;85A6-7) [identified hereafter as $D f(C A 3)]$. Using flanking deficiencies, the $m t g$ gene 
A

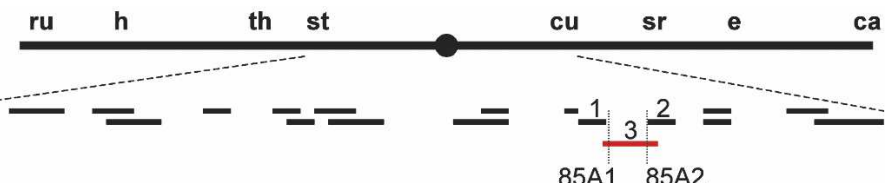

B

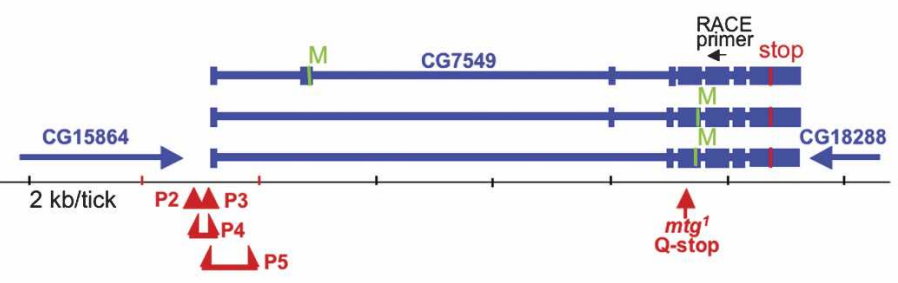

C

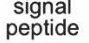
peptide GIn-rich M $\mathrm{Q}_{\mathrm{L} \rightarrow \text { stop }}$

D

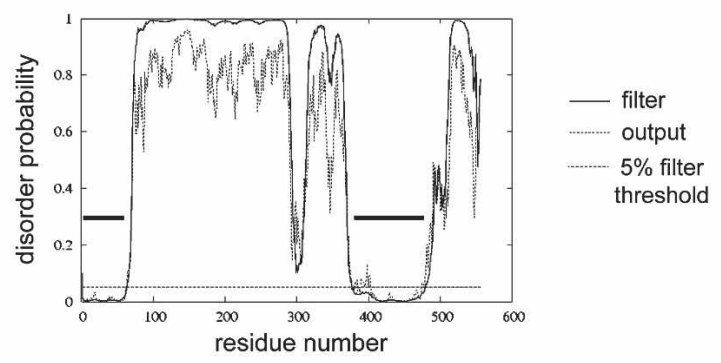

E

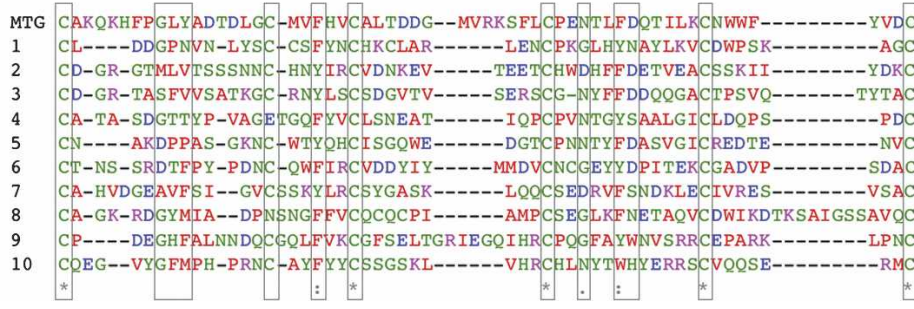

Figure 1. mind the gap (mtg) gene mapping, gene organization, mutant alleles, and MTG protein structure. (A) Recombination and deficiency mapping of $m t g$ on the marked rucuca third chromosome. (ru) roughoid; (h) hairy; (th) thread; (st) scarlet; (cu) curled; (sr) stripe; (e) ebony; (ca) claret. The $m t g$ gene maps between $s t$ and cu. Short bars represent complementing (black) and noncomplementing (red) deletions. Numbered deletions $D f(3 R)$ dsx11 (1), $D f(3 R)$ p-XT103 (2), and $D f(3 R) C A 3(3)$ define the position of $m t g$. The $m t g$ gene maps to $85 \mathrm{~A} 1 ; 85 \mathrm{~A} 2$. $(B)$ The $\mathrm{mtg}$ CG7549 region and organization contained within 85A1-2; introns (narrow bars) and exons (wide bars) are shown in blue, with the first ATGs for each splice form in green (M). Exons 1-6 were found by $5^{\prime}$ RACE. Exons 6-8 were identified by the BDGP EST project. The resulting eight exons encode a novel protein with two predicted products of 62.4 and $43.4 \mathrm{kDa}$, respectively. The $\mathrm{mtg}^{1}$ mutation results in an early termination codon (Q134 to stop) in exon 5 (red arrow). The P-element insertions located within $\left(m t g^{P 3}\right)$ and immediately $5^{\prime}$ to $\left(m t g^{P 2}\right)$ exon 1 , and P-element deletion alleles between exons 1 and 2 $\left(m t g^{P 4}, m t g^{P 5}\right)$, each fail to complement $m t g^{1} .(C)$ Diagram of MTG protein based on amino acid sequence analysis. Positions of the $\mathrm{mtg}^{1}$ nonsense mutation (Q to stop) and the alternative start methionine are shown. (D) Disorder plot of the MTG protein. Two regions of highly ordered structure are indicated by horizontal bars; region 1 (amino acids 1-60) includes the signal peptide and likely represents $\alpha$-helix; region 2 (amino acids 400-475) closely corresponds to the CBM/ ECM-binding domain, an ordered structure with six cysteines predicted to form three disulfide bridges. The solid plotted line (filter) represents predicted disorder probability (DISOPRED); the dotted plot (output) includes shorter regions with lower confidence disorder predictions. The horizontal dashed line represents the order/disorder $5 \%$ threshold $15 \%$ assumed false-positive rate for disorder). (E) Alignment of the MTG predicted GlcNAc-binding domain (amino acids 401-459) with conserved domains. The six consensus cysteines (green) are shown in boxes. Aligned sequences are 1(DQC) crab tachycitin chain A, chitin domain type ChtBD2 (1), (AAF49053) Drosophila peritrophin-A domain CBM14 (2), (AAF49054) CBM14 from CG17145 (3), (AAF49978) CBM14 from CG6947 (4), (AAF49978) CBM14, also in CG6947 (5), (AAF50778) CBM14 in CG4835 (6), (CAB07215) C. elegans peritrophin-A domain ChtBD2 from H02I12.1 (7), (AAF49985) Drosophila peritrophin domain CBM14 from CG7252 (8), (AAF55402) CBM14 from CG4090 (9), and (AAF56085) CBM14 from CG13837 (10).

was mapped to cytological interval 85A1-2. Two P-element insertion lines hopped into this region, $m \operatorname{tg}^{P 2}\left(\mathrm{P}\left[\mathrm{ry}^{+\mathrm{t} 7.2}=\mathrm{RP} 49\right] \mathrm{A} 3 \mathrm{ry}^{506}\right)$ and $\mathrm{mtg}^{P 3}\left[\mathrm{y}^{1}, \mathrm{w}^{1}\right.$; $\mathrm{P}\{\mathrm{lacW}\} 1(3) S O 84910]$ (Fig. 1B), fail to complement $\mathrm{mtg}^{1}$. Homozygous $m t^{P 2}$ and $m t^{1} / \mathrm{mtg}^{P 2}$ transheterozygous embryos display limited coordinated movement within the eggcase, but fail to hatch. Homozygous $\mathrm{mtg}^{P 3} \mathrm{em}$ bryos hatch but move weakly and quickly die as early first instar (L1) larvae; $\mathrm{mtg}^{1} / \mathrm{mtg}^{P 3}$ embryos also die early in L1. Precise excision lines of $\mathrm{mtg}^{P 3}$ are viable and fertile and complement $m \mathrm{tg}^{1}$, showing that the $\mathrm{P}$ element is solely responsible for $m t g$ phenotypes. Additional excision alleles $\left(m t g^{P 4}, m t g^{P 5}\right)$ were made by imprecise Pelement mobilization (Fig. 1B).

To identify the $m t g$ gene, flanking DNA was isolated from both $m t^{P 2}$ and $m t g^{P 3}$ insertions (see Materials and Methods). The $m t^{P 2}$ and $m t g^{P 3}$ insertions are located downstream (335 and 380 nucleotides [nt], respectively) from the TAG stop codon of gene CG15864, and immediately upstream of gene CG7549 (Fig. 1B). All three upstream ORFs (CG33722, CG18749, CG15864) were sequenced in $\mathrm{mtg}^{1}$ mutants and rucuca controls, and no mutant nucleotide changes were found. In contrast, the immediately downstream gene CG7549 contains a single nucleotide change in the ORF coding region, converting Q134 to a stop codon resulting in premature termination (Fig. 1B). 5' RACE (rapid amplification of cDNA end) was used to identify the first three exons, which are not predicted in the existing FlyBase annotation and sequence databases for CG7549, and three alternately spliced CG7549 transcripts (Fig. 1B). The $\mathrm{mtg}^{P 2}$ insertion lies $23 \mathrm{nt}$ upstream of exon 1 , and the $m \mathrm{tg}^{P 3}$ insertion is $14 \mathrm{nt}$ into exon 1 . The $\mathrm{mtg}^{P 4}$ mutation results in a deletion of $95 \mathrm{nt}$, removing $22 \mathrm{nt}$ of exon 1 and 73 upstream nucleotides. The $\mathrm{mtg}^{P 5}$ mutation results in a deletion of $616 \mathrm{nt}$, including the last $49 \mathrm{nt}$ of exon 1 and 
$567 \mathrm{nt}$ of intron 1. Part or all of the original element (P3) is also present in both deletion alleles (Fig. 1B). The $\mathrm{mtg}^{1}$ Q134 point mutation is $102 \mathrm{nt}$ into exon 5. RT-PCR confirmed a predicted reduction in CG7549 mRNA levels for $m t^{P 2}$ (Supplementary Fig. S1), predicting mRNA reductions for the other P-element alleles. The longest $m t g$ transcript encodes a predicted 556-amino-acid, 62.4$\mathrm{kDa}$ protein. The two shorter transcripts lack 5 '-untranslated region (UTR) and exon 2, and initiate at the next available methionine downstream from Q134 in exon 5, encoding predicted proteins of $43.4 \mathrm{kDa}$ (Fig. 1B).

So far, we have been unable to rescue $\mathrm{mtg}$ mutant phenotypes using the GAL4-UAS system to drive ubiquitous (Uh1 Gal4) or nervous system (elav Gal4) expression of a wild-type $m t g$ transgene. A likely explanation is that the Gal4-UAS approach is unable to correctly replicate the endogenous level and pattern of endogenous $\mathrm{mtg}$ gene expression during synaptogenesis. Gal4-driven $m t g$ overexpression may also be deleterious, and therefore prevent mutant rescue. However, the two best alternative proofs provide strong evidence that CG7549 is the $\mathrm{mtg}$ gene. First, precise excision of the P-element in CG7549 $\left(\mathrm{mtg}^{P 3}\right)$ completely rescues the mutant, while the adjacent $\mathrm{P} 4 \mathrm{H}$ gene shows no mutation in $\mathrm{mtg}^{1}$, strongly indicating that this insertion is solely responsible for $m t g$ phenotypes. Second, a transgenic $m t g$ RNA interference (RNAi) line phenocopies $m t g$ lethality and genetically interacts with $\mathrm{mtg}^{1}$, and produces synaptic defects consistent with $m t g$ mutant phenotypes (see below). In all subsequent studies, $D f(C A 3)$ is used as a deletion null, $\mathrm{mtg}^{1}$ as a predicted functional null, and $m \mathrm{tg}^{P 2-P 5}$ as partial loss-of-function hypomorphic alleles.

\section{MTG is a predicted secreted,}

$N$-acetyl-glycosaminoglycan-binding protein

The MTG protein has an N-terminal 19-amino-acid secretion signal peptide, with a cleavage site at T20 (Fig. $1 \mathrm{C})$, and a predicted molecular weight (MW) of $60.2 \mathrm{kDa}$ for the cleaved, secreted product. The $\mathrm{N}$-terminal third of the protein contains a 41-amino-acid, highly glutamine- and leucine-rich domain, predicting an ordered $\alpha$-helical structure (Fig. 1C,D). This domain contains the premature stop codon in $\mathrm{mtg}^{1}$. The C-terminal half of the protein contains a highly structured, 51-amino-acid $\alpha$-helical domain with homology with extracellular carbohydrate-binding (CBM-14/19) and chitin-binding peritrophin-A domains (ChtBD-2) (Fig. 1C-E). Related domains conserved in other extracellular proteins, including the classic synaptic cleft marker wheat germ agglutinin (WGA) (Martin 2002, 2003b), have specific binding affinity for GlcNAc. The structured "ECM-binding" domain contains six conserved cysteines, predicted to form three disulfide bridges stabilizing a folded or knotted structure, and is related to similar extracellular domains within the "cysteine knot"-containing protein superfamily. This family includes carbohydrate-binding lectins (e.g., WGA), knottins, neuronal ion channel-binding toxins, and secreted mucins, glycohormones, and growth factors including EGF and TGFß (Vitt et al. 2001;
Knottin database, http://knottin.cbs.cnrs.fr). The type 1 EGF domain is also present in laminins, which function as ECM integrin-ligands, and many other EGF signaling proteins.

To directly test the prediction that the MTG protein is secreted, an expression vector containing a $\mathrm{mtg}$-GFP fusion construct was transfected into cultured Drosophila S2 cells. Twenty-four hours to $48 \mathrm{~h}$ following induction, MTG-GFP fluorescence was faintly visible in transfected living and fixed cells, compared with more intensely fluorescent Tau-GFP-transfected control cultures. A $105-k D a$ MTG-GFP protein recognized by anti-GFP antibodies, was found on Western gels of MTG-transfected cultures and was absent from Tau-GFP-transfected control cultures (Supplementary Fig. S2; data not shown). The expected size of GFP-tagged MTG is $89 \mathrm{kDa}$, suggesting post-translational modification of the expressed MTG protein (see below). A larger band of $\sim 250 \mathrm{kDa}$ may represent a dimer, or a more highly glycosylated form of MTG-GFP, while a smaller 50-kDa band may represent a cleavage product. All three bands are specific to MTGGFP cultures and are not observed in Tau-GFP-transfected control cultures. The MTG-GFP bands are present in concentrated culture supernatant from MTG-GFPtransfected cultures, consistent with MTG secretion into the extracellular environment (Supplementary Fig. S2). We next used confocal microscopy to image S2 cell MTG-GFP and anti-GFP fluorescence to examine MTG cellular expression, and determine whether secreted protein was localized to the cell surface (Fig. 2A,B). Cultures were processed with detergent (Triton X) or detergentfree conditions to distinguish between total (permeablized) and surface (unpermeablized) protein staining. In detergent-treated cells, MTG-GFP is internally localized in concentrated aggregates, many located peripherally near the cell membrane, as well as diffusely within the cytoplasm (Fig. 2A). With detergent-free staining, MTG-expressing cells were identifiable by internal MTG-GFP expression. Surface anti-GFP staining of MTG-expressing cells typically revealed numerous aggregates distributed to the cell periphery and externally on the cell surface, which could be confirmed by examining $Z$-axis rotations of imaged staining (Fig. 2B). This protein distribution suggests that intracellular MTG protein is aggregated or packaged near the cell surface and secreted, but that secreted protein can remain bound to the cell surface. In contrast, in detergent-free conditions no external anti-GFP staining was detected for nonpermeablized Tau-GFP-expressing cells, despite much higher levels of internal GFP protein, or in untransfected controls, indicating the specificity of MTG-GFP outer surface localization (Fig. 2C).

To directly test the prediction that MTG binds the GlcNAc moiety present on extracellular proteoglycans, we assayed protein binding to GlcNAc-conjugated agarose beads in extracts from wild-type controls and homozygous $D f(C A 3)$ embryos that lack the $m t g$ gene (Fig. 2D). In total protein-stained gels, a number of proteins bind to and are enriched from total lysate by GlcNAc beads (Fig. 2D). Several of these GlcNAc-binding protein 

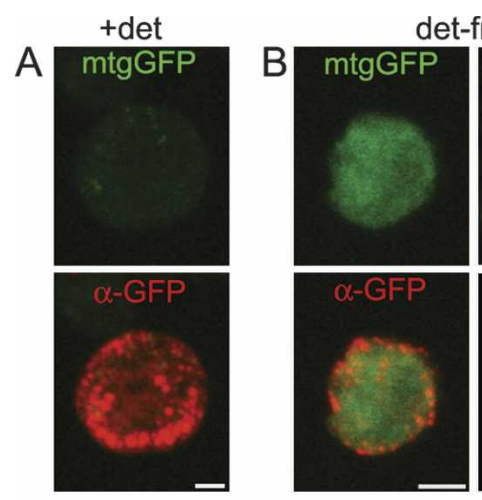

det-free
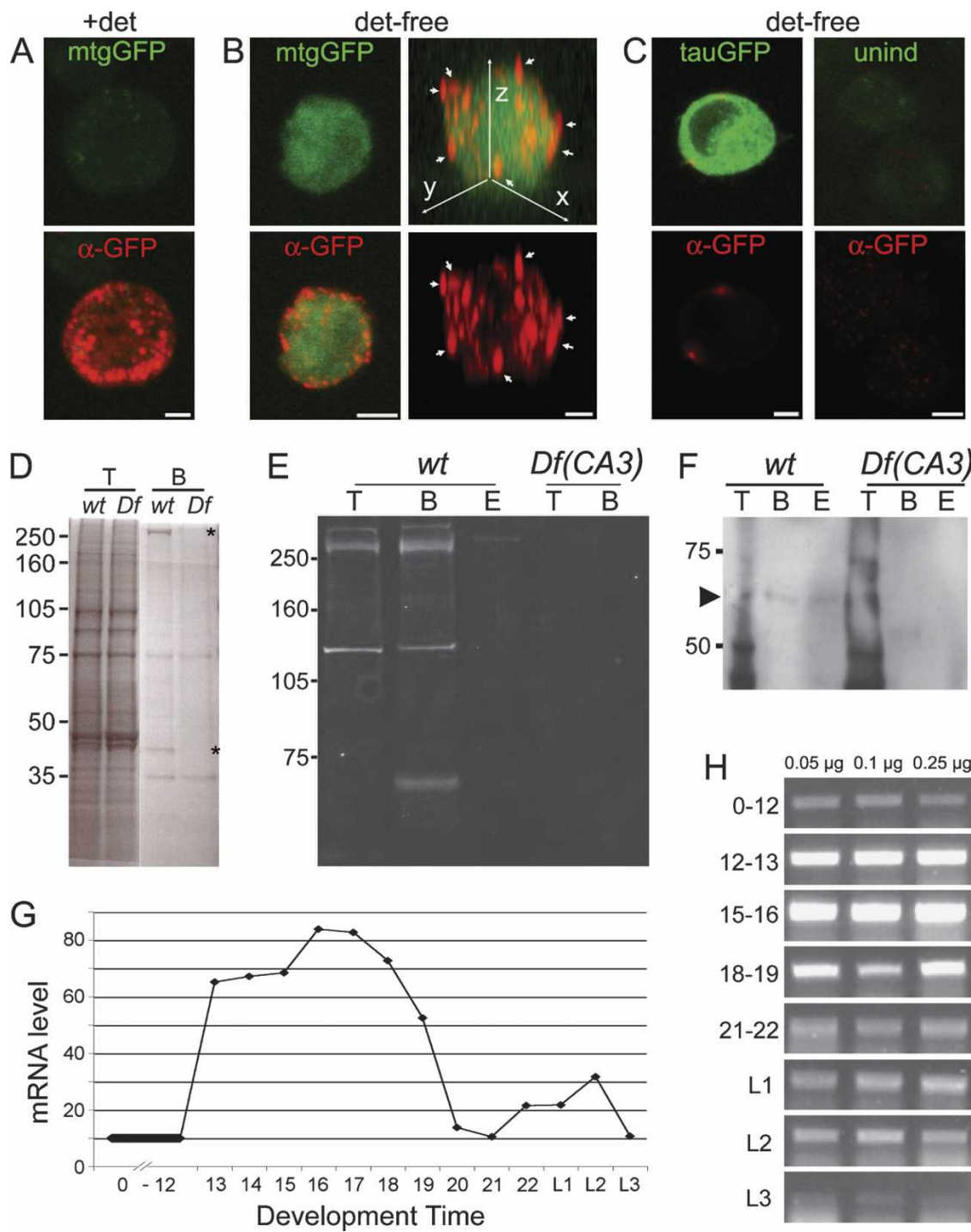
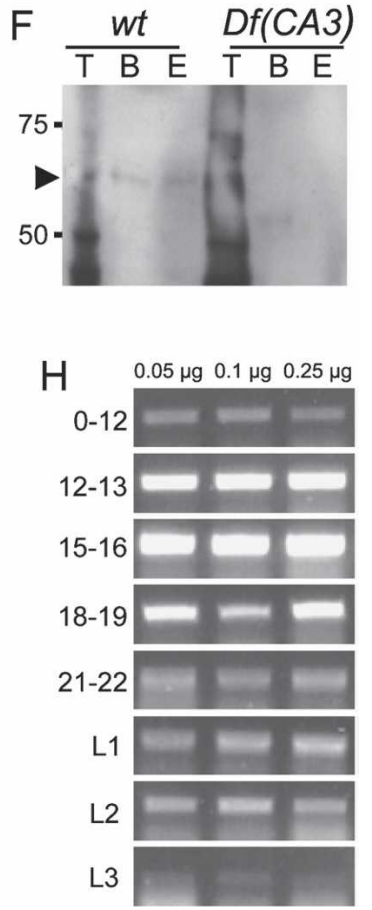

Figure 2. MTG is a secreted, GlcNAcbinding protein with peak expression during embryonic synaptogenesis. $(A-C)$ MTG protein secretion in vitro. (A) MTG-GFP fluorescence (top, green) and anti-GFP staining (bottom, red) in detergent-permeablized Drosophila S2 cell transfected with MTG-GFP. Note that GFP fluorescence is relatively weak in permeablized stained cells. Anti-GFP shows intracellular MTG protein localization in dense aggregates near the membrane. A 3.3- $\mu \mathrm{m}$ Z-projection. Bar, 4 um. (B) MTG-GFP fluorescence (top, green) and anti-GFP staining (bottom, red) in detergent-free (nonpermeablized) MTG-GFP-transfected cell. Anti-GFP labeling reveals numerous external protein aggregates on the cell surface. Left panels show a 3.3-um Z-projection. Right panels show a full rotational $Z$-axis projection of the same cell; arrows point to clear surface anti-GFP punctae on the cell hemisphere. Bars: left, $4 \mu \mathrm{m}$; right, $2 \mu \mathrm{m} .(C)$ Left panels show intracellular Tau-GFP and anti-GFP labeling in detergent-free cell transfected with Tau-GFP. External anti-GFP labeling is virtually absent (2-um Z-projection). Right panels show fluorescence levels in a control detergent-free uninduced S2 cell, stained with anti-GFP (bottom, red; 5- $\mathrm{mm}$ Z-projection). Bar, 4 um. (D) Commassiestained gel showing enrichment of proteins in embryonic lysates by GlcNAc binding. (T) Total lysate; (B) GlcNAc bead-bound fraction, showing a small subset of total protein is enriched by GlcNAc binding. Two proteins (asterisks) enriched from wild-type $(w t)$ embryos are absent from $D f(C A 3)(D f)$ embryos. (E) Western blot probed with anti-MTG (serum 52), showing enrichment of MTG proteins by GlcNAc binding specificity. (T) Total lysate; (B) bead-bound fraction; (E) chitobiose-eluted fraction. Major bands of $>250 \mathrm{kDa}$ and $121 \mathrm{kDa}$ are detected in total lysate and on the GlcNAc beads in wild-type (wt) embryos, but are absent in $D f(C A 3)$ embryos, which are deleted for the $m t g$ gene. A 67-kDa wild-type band is clearly detected after GlcNAc bead enrichment, and is absent in mutant embryos. (Lane $E$ ) In this experiment, the $>250-\mathrm{kDa}$ protein band was only weakly eluted by chitobiose. In another experiment, the eluate contained the 67-kDa band. $(F)$ Western blot of deglycosylated protein preparations, probed with anti-MTG. Bead-bound (B) and chitobiose-eluted (E) protein fractions reveal a wild-type band of the predicted $60-\mathrm{kDa}$ size for MTG (indicated by arrowhead) that is absent from $D f(C A 3)$ lysates. (T) Total lysate. Proteins were deglycosylated after fractionation by GlcNAc beads. $(G) \mathrm{mtg}$ RNA levels during development. $X$-axis shows embryo age in hours, or larval instar stage (L1, L2, L3). Y-axis shows mRNA levels plotted as arbitrary gray-value units from PCR gel bands (see $H$ ). $(H)$ Representative gel lanes showing $m t g$ RT-PCR product at eight stages of development (embryo age in hours, or larval instar stage). Values above each lane indicate total RNA template amount $(0.05 \mu \mathrm{g}, 0.1 \mu \mathrm{g}, 0.25 \mu \mathrm{g})$ used. Band intensity levels for lane 1 (0.05 $\mu$ g template) were used to plot results shown in $G$.

bands are clearly absent in $D f(C A 3)$ lysates (Fig. 2D). Wild-type and mutant embryo protein extracts were next probed by Western blot, using anti-MTG peptide antibodies raised against sequences from the C-terminal half of the protein. Each antibody similarly recognizes multiple protein bands on Western blots of wild-type embryos. To enrich MTG product and confirm predicted MTG binding specificity, GlcNAc-conjugated beads were used to concentrate proteins from total embryonic lysate. Anti-MTG detectably recognized proteins of 121
$\mathrm{kDa}$ and $>250 \mathrm{kDa}$ in total lysate (Fig. 2E). The GlcNAc bead-enriched fraction contained the $121-\mathrm{kDa}$ and $>250$ $\mathrm{kDa}$ proteins, as well as a $67-\mathrm{kDa}$ band recognized by anti-MTG. All three bands were absent in $\mathrm{mtg}$-null $\mathrm{mu}-$ tants (Fig. 2E), suggesting three MTG isoforms. MTG was only weakly eluted from the beads by $N, N^{\prime}$-diacetylchitobiose, a dimer of GlcNAc. The MTG protein contains two predicted $\mathrm{N}$-glycosylation sites, and five mucin-type, GalNAc O-glycosylation sites. The larger MW MTG-immunoreactive proteins therefore likely 
represent glycosylated forms of the $60.2-\mathrm{kDa} \mathrm{MW}$ protein predicted by primary sequence. To test this hypothesis, the lysate, bead-bound, and eluted protein fractions were each enzymatically deglycosylated (see Materials and Methods). Following deglycosylation, the beadbound and eluted fractions show a single weak MTGimmunoreactive band of $\sim 60 \mathrm{kDa}$, equal to the predicted MW of MTG (Fig. 2F). This band was absent from $D f(C A 3)$ bead and eluted fractions, indicating its specificity. These results show that MTG is a secreted glycosylated protein, and binds the extracellular GlcNAc moiety known to be concentrated within the synaptic cleft.

\section{MTG expression peaks during embryonic NMJ synaptogenesis}

Assays of $m t g$ mRNA levels throughout development show that mRNA abundance is very low during the first half of embryogenesis (0-12 $\mathrm{h}$ after fertilization). Expression increases sharply at $12-13 \mathrm{~h}$ to a peak level at 16-17 $\mathrm{h}$, then declines sharply from 18 to $20 \mathrm{~h}$ (Fig. 2G,H). Message level persists at a low level throughout late embryogenesis and subsequent larval stages, with a small transient peak during L2. Expression again transiently increases on the third day after pupariation, and declines prior to adult eclosion (data not shown). In the adult, the $m t g$ message in the head is elevated relative to the rest of the body, consistent with neuronal function. The developmental $\mathrm{mtg}$ expression pattern therefore correlates closely with known periods of synaptogenesis (Broadie and Bate 1993a,c) and the expression profiles of other known synaptic genes, suggesting an important role for $m t g$ in this process. For example, still life (sif), a presynaptic rho-GEF required for synaptogenesis, is expressed from $16 \mathrm{~h}$ in the embryo (Sone et al. 1997). Hikaru genki (hig), a secreted synaptic cleft protein important for adult central synaptogenesis, is likewise highly expressed at $16-24 \mathrm{~h}$ in embryonic neurons, as well as in the late pupa (Hoshino et al. 1996, 1999).

Dissected control and mutant embryos were assayed with anti-MTG antibodies to examine MTG protein localization, in combination with neuronal and synaptic markers. Mature 20- 22-h mutant embryos $\left[\mathrm{mtg}^{1} / \mathrm{mtg}^{1}\right.$ and $\left.m \operatorname{tg}^{1} / D f(C A 3)\right]$ probed with the anti-horsradish peroxidase (HRP) neuronal membrane marker display morphologically normal CNS and ventral nerve cord (VNC), and normal peripheral axon extension, branching, and targeting (Fig. 3A,B; data not shown). NMJ formation and presynaptic terminals appear correctly and stereotypically formed (Fig. 3B; see also Figs. 6, 7, below). In control wild-type embryos, anti-MTG staining shows expression in the CNS, VNC, and body wall musculature (Fig. $3 \mathrm{~A}, \mathrm{~B})$. MTG staining is notably concentrated within embryonic neuronal cell bodies, including identified motor neurons at the VNC midline, and motor neurons in lateral VNC regions (Fig. 3A), and is also detectable in segmental nerves and peripheral nerve branches, consistent with a neuronal expression pattern. MTG muscle staining is present in proximity to NMJs, but is not selectively enriched at embryonic NMJs (Fig. 3B). MTG stain- ing level is clearly reduced in homozygous $\mathrm{mtg}^{1}$ and $m \operatorname{tg}^{1} / D f(C A 3)$ mutant embryos (Fig. 3A,B). As noted above, $m t^{1}$ mutants potentially synthesize a short MTG isoform recognized by anti-MTG Abs, which may account for residual staining in mutants. We further assayed MTG staining in mtg RNAi larvae ubiquitously expressing UAS-mtg-RNAi (UH1-Gal4/UAS mtg RNAi; Fig. 3C). Ubiquitous RNAi animals have significantly reduced $\mathrm{mtg}$ transcript levels at embryonic stages (see below), and die as seceond instar larvae. At control larval NMJs double-stained for synaptic markers, MTG staining is clearly concentrated to synaptic or perisynaptic regions at many terminals, and also concentrated at muscle ends and muscle attachment sites, where other synaptic scaffolding, cytoskeletal, and ECM proteinsincluding dPak, Dlg, and integrins-are developmentally expressed (Fig. 3C). MTG level is clearly reduced throughout mtg RNAi larvae, including neuronal, muscle, and NMJ regions (Fig. 3 C). Since mtg mRNA level peaks at 16-17 h, during early-mid stages of embryonic synaptogenesis, these results suggest that MTG protein becomes increasingly concentrated at the NMJ during development.

\section{MTG expression at NMJ boutons and synaptic cleft}

MTG staining is reproducibly detected at NMJ boutons in third instar larvae (Fig. 3D,F). At a confocal imaging level, MTG bouton staining partly overlaps with HRPstained presynaptic terminal membrane, as well as with Dlg-stained post-synaptic subsynaptic reticulum (SSR) membrane domains (Fig. 3D,F; data not shown), in addition to associated perisynaptic regions. The pattern of anti-MTG localization at larval NMJs also resembles the NMJ labeling pattern of the GlcNAc-specific lectin WGA (Fig. 3E), strongly suggesting that Drosophila synaptic extracellular and cleft matrix is concentrated in GlcNAc molecules recognized in common by both MTG and WGA. To more precisely localize MTG synaptic localization, immuno-EM studies were conducted using four anti-MTG sera and secondary immunogold labeling (10 or $25 \mathrm{~nm}$ colloidal gold) (Fig. 3G-I). Quantified measurements of labeling incidence and density were made in image profiles that included presynaptic boutons, active zones (AZ), post-synaptic SSR, and an area of surrounding nonsynaptic muscle $(25,000 \times$ magnification) (Fig. 3G-I; Supplementary Table S1). MTG gold grains were consistently detected in both synaptic and perisynaptic domains, with $\sim 60 \%$ of label detected in presynaptic boutons and surrounding SSR ( $n=52$ profiles). At higher magnification, label is detected within several specific synaptic subdomains (Fig. 3G-I). In 35 out of 52 profiles, gold grains were localized within the presynaptic terminal, in many cases (20 out of 35) with grains closely associated with the plasma membrane (Fig. 3G). In several terminals, multiple gold grains were concentrated within an $\sim 100 \mathrm{~nm}$ radius (Fig. $3 \mathrm{H}$ ), consistent with packaging of MTG protein within secretory vesicles. In $96 \%$ of the sections examined (50 out of 52), gold grains were located within the SSR domain (Fig. 


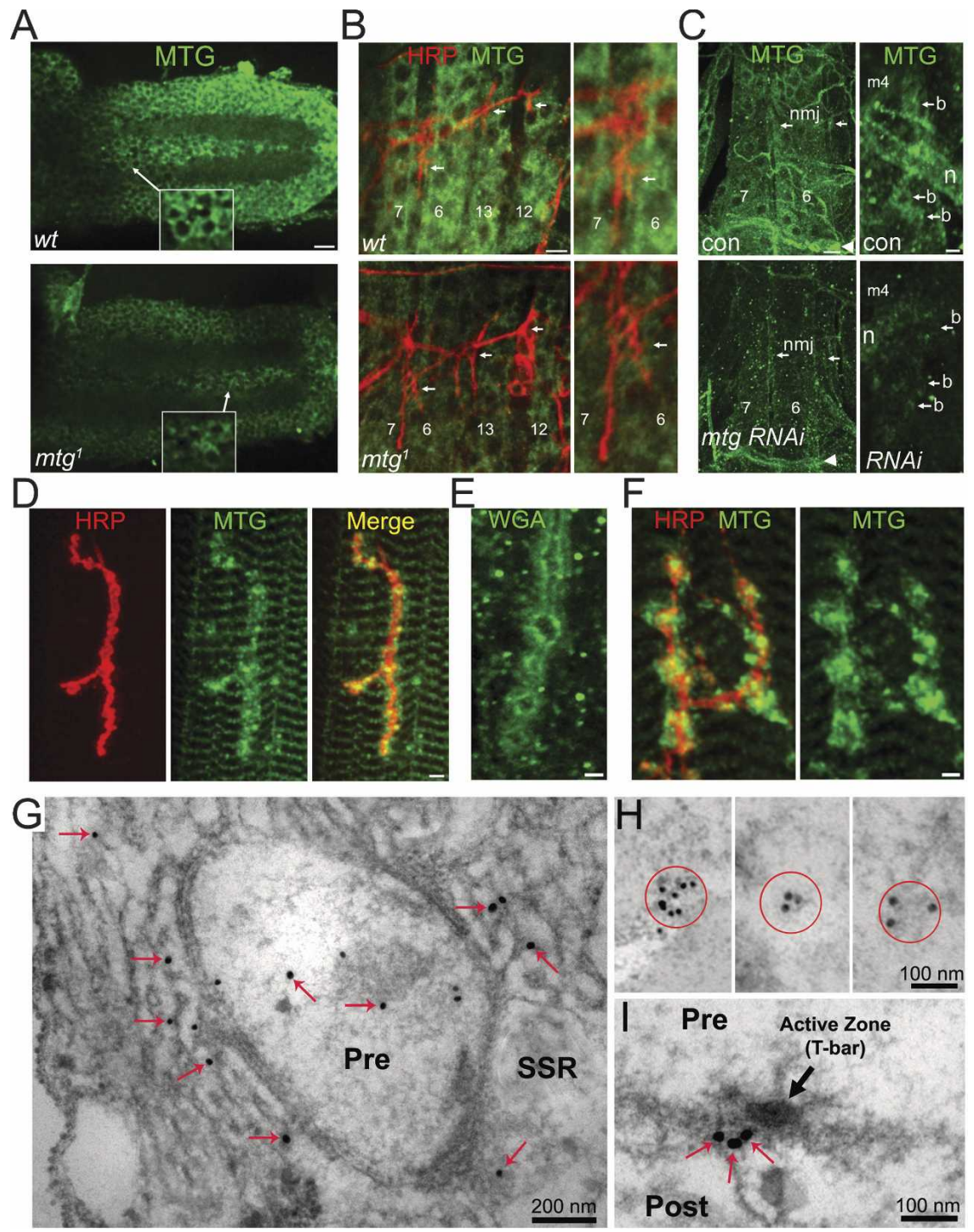

Figure 3. MTG protein distribution and synaptic localization during embryonic and larval development. (A) Anti-MTG staining in 20- to 22-h wild-type (wt, top) and $m t^{1}$ (bottom) embryonic ventral nerve cords (10$\mu \mathrm{m} \mathrm{Z}$-projections). MTG staining is concentrated within neuronal cell bodies, and is visible along the midline and in lateral regions. Insets show neuronal localization at $2 \times$ increased magnification $(2.4-\mu \mathrm{m}$ Z-projections) in midline motor neurons. MTG level is strongly decreased in $\mathrm{mtg}^{1}$ mutant. Bars: $10 \mu \mathrm{m}$; insets, $5 \mu \mathrm{m}$. (B) Anti-MTG (green) and HRP (red) staining at the NMJ in 20- to 22-h wild-type (top) and $\mathrm{mtg}^{1}$ embryos (bottom). Left panels show muscles and NMJs 7/6/13/12 (arrows). Muscle appearance, neuronal axon targeting, synapse formation, and presynaptic terminal morphology (HRP staining, red) in $\mathrm{mtg}^{1}$ and $m \operatorname{tg}^{1} / D f C A 3$ mutants are comparable with wild type. MTG staining is present in muscle fields, and is detectable in segmental nerves and nerve branches. Right panels show NMJ $6 / 7$ at $2 \times$ increased magnification. Anti-MTG staining intensity is strongly reduced though not eliminated in $m \operatorname{tg}^{1}$ and $m \mathrm{tg}^{1} / \mathrm{DfCA} 3$ mutants. Bars: left, 5 $\mu \mathrm{m}$; right, $2.5 \mu \mathrm{m}$. (C) Anti-MTG staining in second instar driver control (UH1 Gal4; top) and $m t g$ RNAi larva (UH1 Gal4/UAS mtg RNAi; bottom). (Left) Muscles 6/7, showing MTG staining throughout the muscle and strongly concentrated at the muscle attachment regions (arrowheads). MTG enrichment is also evident at many NMJs (arrows indicate NMJs 6/7 and 13). (Right) MTG staining at the muscle 4 NMJ. (n) Nerve; (b) boutons. MTG staining level is clearly and consistently reduced by ubiquitous RNAi. Bars: left, $10 \mu \mathrm{m}$; right, $5 \mu \mathrm{m}$. (D) Anti-MTG (green) and HRP (red) colabeling at third instar larval NMJ. Anti-MTG is concentrated in and surrounding many NMJ boutons, as well as in some nonsynaptic muscle patches, consistent with both pre- and post-synaptic expression. Bar, $5 \mu \mathrm{m}$. (E) WGA lectin staining at the larval NMJ, confirming the presence of GlcNAc-containing ECM and synaptic cleft molecules. Bar, $2.5 \mu \mathrm{m}$. (F) Higher-magnification example of concentrated anti-MTG localization pre- and post-synaptically at wild-type NMJ boutons colabeled with HRP (red). (G-I) Anti-MTG immuno-EM at larval NMJs. (G) Twenty-five-nanometer immunogold labeling (arrows) within the presynaptic terminal (Pre) and post-synaptic SSR. Bar, 200 nm. (H) Examples of 10-nm (left) and 25-nm MTG immunogold labeling (middle and right) clustered within presynaptic terminals. Bar, $100 \mathrm{~nm}$. (I) AZ and T-bar region (black arrow) showing four immunogold grains (red arrows) localized within or immediately adjacent to the synaptic cleft under the AZ. Bar,100 nm.

3G). SSR-localized grains made up $\sim 36 \%$ of the total grains scored/section, and were distributed both singly and as localized clusters, suggesting MTG protein is spatially concentrated within the SSR. Strikingly, in $\sim 35 \%$ of profiles (18 out of 52) one or more gold grains was located within a defined area $\left(0.098 \mathrm{\mu m}^{2}\right)$ encompassing the AZ and synaptic cleft. In the majority (10 out of 18) of these instances, gold label was specifically localized to the extracellular synaptic cleft domain immediately under an AZ T-bar structure (Fig. 3I), confirmed by serial sectioning. Quantified gold mean labeling density within defined AZ areas was threefold higher $(7.8 \pm 1.2$ $\left.\mu \mathrm{m}^{-2}\right)$ than within presynaptic boutons $\left(2.5 \pm 0.5 \mu \mathrm{m}^{-2}\right)$ or post-synaptic SSR domains $\left(2.4 \pm 0.4 \mu^{-2}\right)$ (Supplementary Table S2). MTG localization both within presynaptic boutons and the post-synaptic SSR is consistent with its secretion at the NMJ synapse. In particular, MTG localization by immuno-EM to the synaptic cleft domain supports the hypothesis that MTG is secreted to function within the synaptic cleft matrix.

\section{MTG is required for functional post-synaptic differentiation}

To determine the cause of $m t g$ mutant paralysis, wholecell patch-clamp recordings were made from muscle 6 at 
the mature embryonic (20-22 h) NMJ synapse (Fig. 4). Wild-type NMJs exhibit large amplitude (1-1.5 nA) spontaneous excitatory junctional currents (EJCs) driven by spontaneous neuronal action potentials, and occasional patterned EJC bursts driven by central locomotory generator activity (Broadie and Bate 1993c; Baines et al. 1999, 2001). In $\mathrm{mtg}^{1} / \mathrm{mtg}^{1}$ and $\mathrm{mtg}^{1} / \mathrm{Df}(\mathrm{CA3})$ mutant embryos, this endogenous transmission activity is largely silenced. Occasional isolated mutant EJCs are recorded, demonstrating functional transmission; however, $m$ tg terminals display only small amplitude EJCs, and patterned bursts of large EJCs are not observed. Motor nerve stimulation $(1 \mathrm{~Hz})$ evokes robust EJCs with $100 \%$ reliability in wild-type and $\mathrm{mtg}^{1} /+$ controls (mean amplitude $1274 \pm 169$ pA) (Fig. 4A,B). In contrast, homozygous $\mathrm{mtg}^{1}$ and $m \mathrm{tg}^{1} / \mathrm{Df}(\mathrm{CA3})$ NMJs exhibit severely
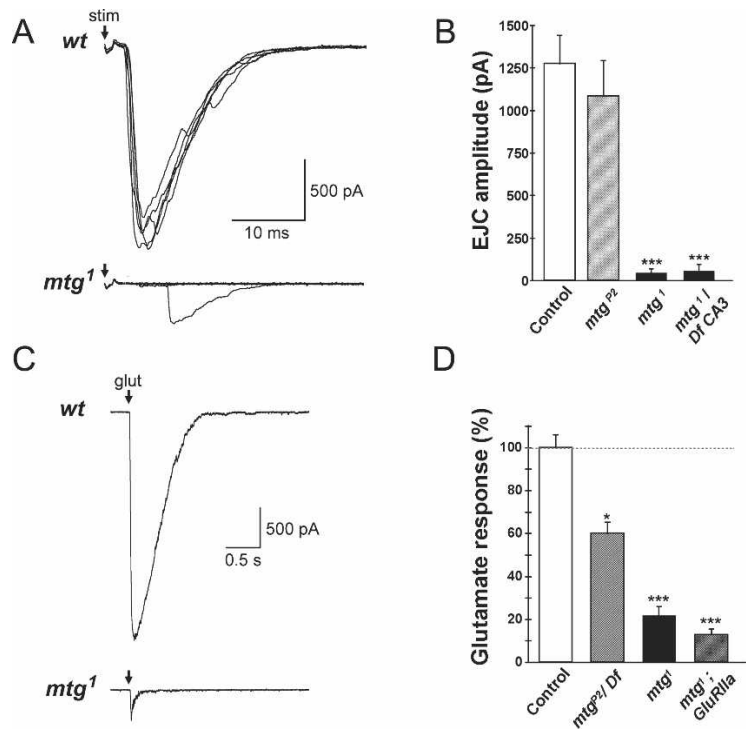

Figure 4. Impaired synaptic transmission at $m$ tg mutant NMJs is due to loss of post-synaptic GluR function. (A) EJCs evoked by $1-\mathrm{Hz}$ segmental nerve stimulation at wild-type control (top traces) and homozygous $\mathrm{mtg}^{1}$ mutant NMJs (bottom traces). Five consecutive responses are superimposed for both recordings, illustrating the frequent $(\sim 9 \%)$ transmission failures at $m t^{1}$ and $m t^{1} / D f(C A 3)$ NMJs. Recordings made in whole-cell mode at $-60 \mathrm{mV}$ from muscle 6 (A2-A3). (B) Quantified mean EJC amplitudes for controls (wild type and $m \operatorname{tg}^{1} /+; n=4$; unshaded bar), $m t^{P 2} / \mathrm{mtg}^{P 2}$ (lightly shaded; $n=5$ ), and $\mathrm{mtg}^{1} / \mathrm{mtg}^{1}$ $(n=7)$ and $\mathrm{mtg}^{1} / \mathrm{Df}(\mathrm{CA})$ (solid bars; $n=7$ for each allele). For $m t^{1}$ and $m t^{1} / \mathrm{Df}(\mathrm{CA} 3)$ alleles, overall severity of evoked transmission loss is $>90 \%$. $\left.^{\star \star \star}\right) P<0.005$ versus control. $(C)$ Postsynaptic GluR currents evoked by focal glutamate application to muscle 6/7 NMJ. Traces shown are representative responses to puffer-applied $1 \mathrm{mM}$ glutamate (200 $\mathrm{msec}$, arrows) in wild type $(w t)$ and $\mathrm{mtg}^{1}$ mutants. (Bottom trace) Glutamate responses are greatly reduced in $\mathrm{mtg}^{1}$ mutants, indicating a loss of GluR function. $(D)$ Quantified glutamate response amplitudes in control [wild type and $D f(C A 3) /+$ ] $, \mathrm{mtg}^{P 2} / D f(C A 3), \mathrm{mtg}^{1}$, and $m \operatorname{tg}^{1}$ mutants with post-synaptically overexpressed GluRIIA (MHC gal4/UAS GluRIIA; $\left.\mathrm{mtg}^{1}\right)$. Mutant response amplitude is normalized to paired control [wild type and $D f(C A 3) /+$ ] responses recorded under identical conditions. Asterisks indicate significance at $P=0.05\left(^{\star}\right)$ and $P=0.005\left({ }^{\star \star}\right)$ versus control. impaired evoked transmission amplitude and reliability. Approximately $90 \%$ of nerve stimuli at $m \mathrm{tg}^{1}$ and $m \mathrm{tg}^{1} /$ $D f(C A 3)$ mutant NMJs result in transmission failure, even with elevated stimulation intensities, while evoked mutant EJCs have reduced amplitudes and more variable response latencies than at control NMJs (Fig. 4A). Mean mutant evoked transmission amplitude is depressed by $>90 \%\left[\mathrm{mtg}^{1}: 46 \pm 23 \mathrm{pA}, n=7 ; \mathrm{mtg}^{1} / D f(C A 3): 57 \pm 44 \mathrm{pA}\right.$, $n=7 ; P<0.005$ vs. control for both alleles] (Fig. 4B). Homozygous $\mathrm{mtg}^{1}$ and $m \mathrm{tg}^{1} / \mathrm{Df}(\mathrm{CA3})$ transmission levels do not differ significantly from each other, confirming that $m \mathrm{tg}^{1}$ behaves functionally as a null mutant. The $m \mathrm{tg}^{P 2}$ allele, which displays movement in the eggcase but fails to hatch, exhibits insignificantly reduced evoked EJC amplitude compared with control (1085 \pm 208 pA, $n=5)$, consistent with a hypomorphic phenotype (see also below). These results show that MTG function is required for the maturation of NMJ synaptic function.

To determine whether the transmission impairment is pre- or post-synaptic, GluR-gated currents were recorded in response to focally applied L-glutamate, applied either by pressure application (Featherstone et al. 2000, 2002) or iontophoresis (Rohrbough et al. 2004), which maximally activates the synaptic GluR population, allowing assessment of overall receptor function. Glutamate response is severely reduced at mtg mutant synapses, indicating that mutant evoked transmission deficits are due largely or entirely to a deficit in post-synaptic GluR function (Fig. 4C). In $\mathrm{mtg}^{1}$ mutants, mean glutamate response amplitude is reduced to $20.8 \pm 4.1 \%$ of control (Fig. 4D). Glutamate response amplitude is also significantly reduced in $\mathrm{mtg}^{P 2} / \mathrm{Df}(\mathrm{CA3})$ embryos $(60.2 \pm 5.4 \%$ of control; $P<0.02 ; n=6$ ) (Fig. 4D), confirming that $m t^{P 2}$ behaves as a hypomorphic $m t g$ allele. As a further functional post-synaptic assay, miniature EJCs (mEJCs) were recorded in saline containing $0.5 \mathrm{mM}$ external $\mathrm{Ca}^{2+}$ and TTX to block spontaneous action potentials. Under these conditions, mEJCs are presumed to represent the activation of single, distinct post-synaptic GluR aggregates by spontaneous presynaptic vesicle fusion and quantal transmitter release. The $\mathrm{mtg}^{1} \mathrm{mEJC}$ mean amplitude is significantly reduced (wild type: $83 \pm 9$ pA, $n=7 ; \operatorname{mtg}^{1}: 58 \pm 9 \mathrm{pA}, n=9 ; P<0.01 ; \mathrm{mtg}^{P 2}: 110 \pm 19$ pA, $n=5 ; P>0.2)$, indicating a decrease in functional synaptic GluRs. Mean mEJC frequencies did not vary significantly between wild type $\left(5.0 \pm 1.3 \mathrm{~min}^{-1}\right), \mathrm{mtg}^{P 2}$ $\left(6.4 \pm 1.7 \mathrm{~min}^{-1} ; P>0.10\right.$ vs. wild type), and $\mathrm{mtg}^{1}$ $\left(8.7 \pm 1.2 \mathrm{~min}^{-1} ; P>0.05\right.$ vs. wild type). To test whether the mutant post-synaptic impairment is rescuable by an exogenous supply of receptor, dGluRIIA-myc was overexpressed under endogenous genomic control in $\mathrm{mtg}^{1}$ mutants. Glutamate responses in $\mathrm{mtg}^{1}$; GluRIIA-myc embryos remain at the severely impaired amplitudes of $\mathrm{mtg}^{1}$ mutants (Fig. 4D), suggesting a defect in GluR function downstream from receptor gene expression.

\section{MTG is required to form the synaptic cleft matrix}

Synaptic ultrastructure was examined by electron microscopy to assess overall pre- and post-synaptic mor- 
phology, as well as identify any structural changes correlated with post-synaptic dysfunction. Presynaptic bouton morphology and appearance, plasma membrane topology, and electron-dense AZ with T-bars all appear normal in mtg-null mutants $\left[\mathrm{mtg}^{1} / \mathrm{mtg}^{1}\right.$ and $\mathrm{mtg}^{1} /$ $D f(C A 3)$ ], with no obvious defects (Fig. 5A). Quantified comparisons between control and mutants showed no significant differences $(P \geq 0.3)$ in mean mutant bouton cross-sectional area, mitochondria size, or number of synaptic vesicles clustered at AZ (Fig. 5A; data not shown). Mutant terminals exhibit a significant increase in the incidence of plasma membrane cisternae structures, a $33 \%$ increase in total synaptic vesicle density $(P<0.001$ vs. wild type $)$ and an increase in vesicles docked at the presynaptic membrane (mtg: $3.6 \pm 0.4$, wild type: $2.2 \pm 0.3 ; P<0.01 ; n=48)$. These presynaptic changes cannot account for the post-synaptic dysfunction, but the increase in vesicle density and docked vesicles could potentially represent an additional deficit in secretory processes, or a compensatory response to a loss of post-synaptic GluR function (DiAntonio et al. 1999), in the absence of MTG.

The synaptic cleft and post-synaptic domains in $m t g$ mutants both exhibit overtly abnormal ultrastructural profiles. Wild-type synapses are characterized by strongly electron-dense pre- and post-synaptic mem- branes, and a prominent, highly electron-dense matrix, which is tightly restricted to the extracellular space between electron-dense pre- and post-synaptic membranes immediately underlying the AZ (Fig. 5A,C). In mtg-null mutants, the electron-dense matrix material is greatly reduced or strikingly absent (Fig. 5C). In wild-type and $\mathrm{mtg}^{1} /+$ controls, only $20 \%$ of synapses contain light/absent synaptic cleft matrix; in contrast, a loss or reduction of cleft matrix is apparent at $60 \%$ of mutant synapses. This phenotype is specific to the cleft matrix domain, since normal AZ T-bars are nevertheless present presynaptically at mutant synapses lacking electron-dense cleft matrix (Fig. 5C). Post-synaptically, $>80 \%$ of wild-type synapses are packed with electron-dense, 20-nm structures shown previously to be polyribosomes that mediate local translation of post-synaptic proteins, including GluRs (Sigrist et al. 2000). This polyribosome domain lies directly opposite and adjacent to the presynaptic AZ and synaptic cleft (Fig. 5A-C). Post-synaptic polyribosomes are clearly reduced in number and density at $>65 \%$ of $m t g$ mutant synapses, and instead are typically found in dispersed patches, rather than the tight packing found in normal post-synaptic domains (Fig. 5B). Therefore, loss of the local post-synaptic ribosome population may contribute to the loss of GluR responsiveness in the absence of MTG.

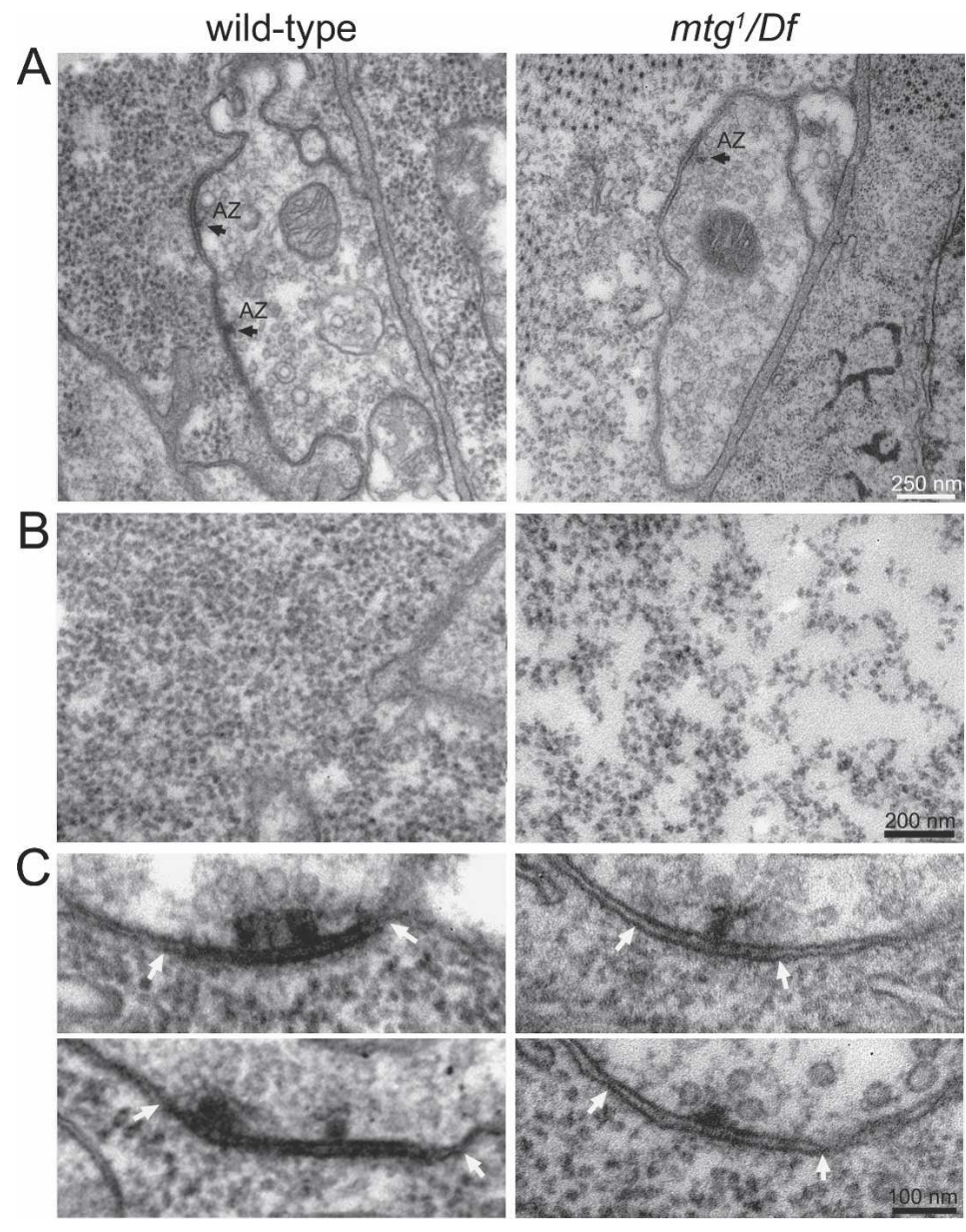

Figure 5. Ultrastructural analyses reveal specific loss of synaptic cleft matrix and post-synaptic polyribosome compartment in $m t g$ mutants. (A) TEM of wild-type control (left) and $\mathrm{mtg}^{1} / D f(C A 3)$ mutant (right) NMJ boutons, showing normal mutant terminal size, morphology, and synaptic vesicle distribution. AZ are visible in both panels as electron-dense synaptic membranes and cleft ECM. The $m t g$ mutant synapse displays a loss of the synaptic cleft density. Bar, $250 \mathrm{~nm}$. (B) Post-synaptic domains located opposite the AZ. (Left) At wild-type synapses, this domain is densely packed with electron-dense polyribosome structures. (Right) In contrast, mtg mutant synapses exhibit reduced polyribosome number and density. Bar, $200 \mathrm{~nm}$. (C) Top and bottom panels show serial images of a single AZ and synaptic cleft region in greater detail. (Left) The wild-type AZ (arrows) is clearly demarked by electron-dense synaptic plasma membranes, and a dense cleft ECM located only at the synaptic interface. In contrast, $m t g$ mutants exhibit a striking loss of electron-dense cleft matrix, resulting in a visible gap between the presynaptic AZ and post-synaptic membrane Bar, $100 \mathrm{~nm}$. 


\section{MTG is required for formation of post-synaptic GluR domains}

The loss of post-synaptic function in $\mathrm{mtg}$ mutants could be due to either a failure to form post-synaptic GluR domains apposing presynaptic AZ or a loss of GluR function, or a combination of both. To address these possibilities, GluR localization and distribution was examined using antibodies against the requisite receptor subunits IIC and IID (Fig. 6). Both IIC and IID are contained in all known GluRs, and therefore reveal the total GluR population in the embryonic muscle and developing NMJ (Featherstone et al. 2005; Qin et al. 2005; DiAntonio 2006). In wild-type control embryonic synapses, GluRs are tightly localized to NMJ domains and present at only a low level in extrasynaptic regions of the muscle (Fig. 6A,B). Synaptic GluRs are aggregated into numerous distinct puncta, closely opposed to individual presynaptic AZ. In $\mathrm{mtg}^{1} / \mathrm{mtg}^{1}$ and $m \mathrm{tg}^{1} / \mathrm{Df}(\mathrm{CA} 3)$-null mutants, this characteristic synaptic localization is largely lost. For both GluRIIC (Fig. 6A) and GluRIID staining (Fig. 6B), mtg mutants show a loss of GluR puncta specifically clustered opposite the presynaptic terminal, and GluR staining dispersed in nonsynaptic muscle areas. Mutant
GluRs appear to form small aggregates, but there is no preferential synaptic targeting or enrichment of these aggregates. These results suggest that GluRs in $\mathrm{mtg}$ mutants are synthesized and assembled, but are either incorrectly localized to extrasynaptic regions, or fail to be retained in post-synaptic domains and so disperse to nonsynaptic areas. Moreover, dispersed receptors are largely nonfunctional, or not located on the cell surface, since neither puff-applied nor iontophoretically applied glutamate evokes a substantial mutant post-synaptic current in physiological recordings (Fig. 4C,D). MTG thus clearly plays a critical role in the post-synaptic localization of GluRs, and the specific targeting of GluR to punctate domains opposite to presynaptic AZ. The loss of GluR localization provides a mechanistic explanation for the functional silencing of the $m t g$ mutant synapse.

\section{MTG acts upstream of the post-synaptic pathways localizing GluRs}

Previous studies have characterized the dPix-dPak-DlgDock molecular pathways regulating GluR localization at the Drosophila NMJ (Parnas et al. 2001; Albin and
Figure 6. Post-synaptic GluRs are severely mislocalized at embryonic $m t g$ mutant NMJs. (A) Mature embryonic (20-22 h) wild-type (top) and $\mathrm{mtg}^{1}$ mutant (bottom) NMJs costained against HRP (red) and the requisite GluRIIC subunit (green) contained in all GluR. Arrows in middle and right panels indicate NMJs 6/7, 13, and 12. Mutant GluR are dispersed or mislocalized to nonsynaptic muscle regions. Synaptic punctae are indistinct or absent in the mutant. Bar, $5 \mu \mathrm{m}$. (B) Higher-magnification images of NMJs 12 and 13 in wild type (top) and $\mathrm{mtg}^{1}$ mutant (bottom) costained against HRP and the requisite GluRIID subunit (green). Mutant GluR exhibit similar nonsynaptic mislocalization/ dispersal and an absence of resolved synaptic punctae. Bar, $2 \mu \mathrm{m}$.
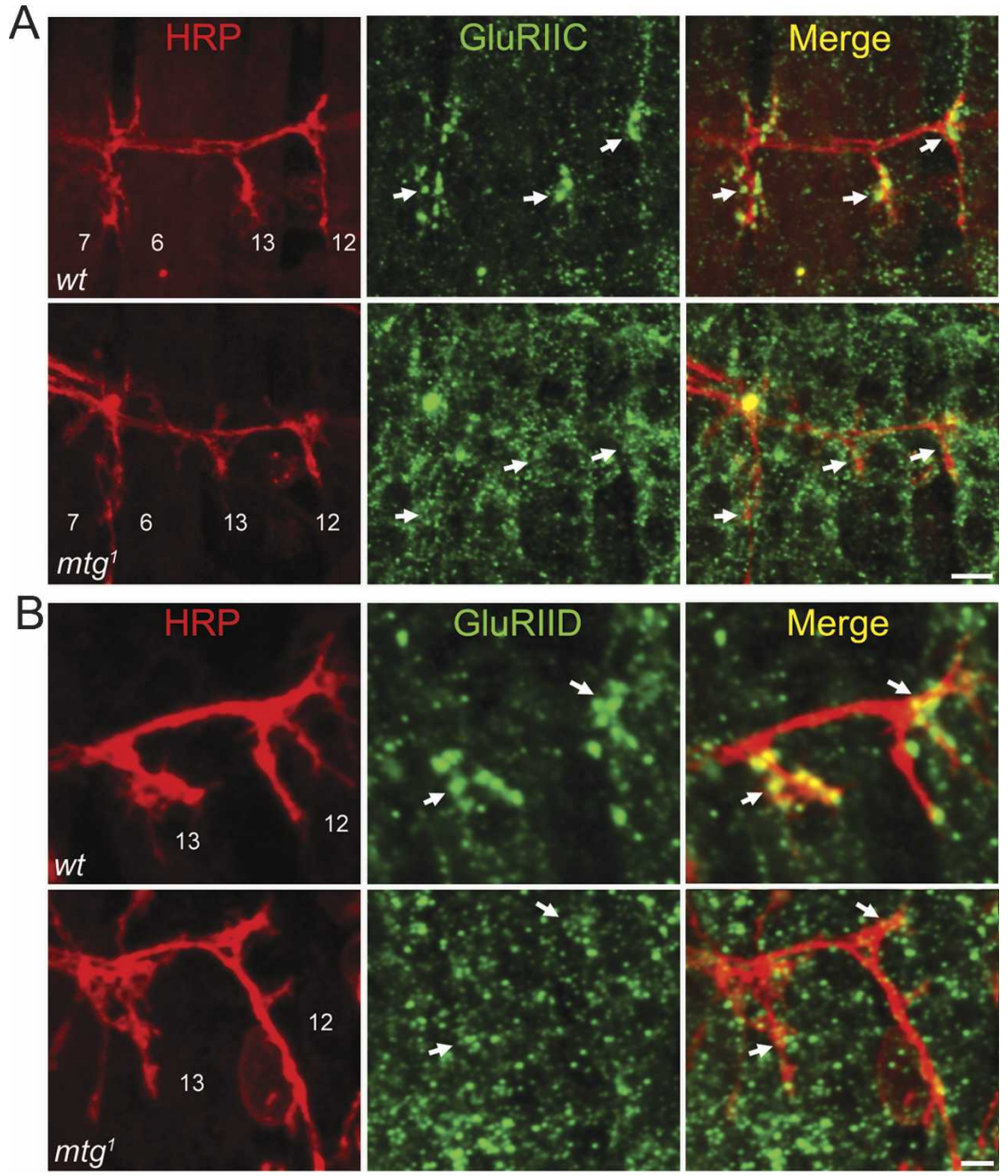
Davis 2004; Chen and Featherstone 2005; Chen et al. 2005). Our results indicate that MTG is secreted and acts within the synaptic cleft matrix, predicting that MTG should act in, or upstream of, the established post-synaptic GluR localization pathways. To investigate whether the loss of MTG disrupts these signaling pathways, we next examined synaptic expression levels and the spatial distribution of dPix, dPak, Dlg, and Dock in control and mtg mutant embryos (Fig. 7).

The PDZ-domain synaptic scaffold Dlg plays critical roles in the post-synaptic localization of numerous proteins including GluRs (Chen and Featherstone 2005). Dlg is strongly expressed at wild-type embryonic NMJs in a post-synaptic region overlapping with and surrounding the presynaptic terminal (Fig. 7A). In $\mathrm{mtg}^{1} / \mathrm{mtg}^{1}$ and $\mathrm{mtg}^{1} / \mathrm{Df}(\mathrm{CA3})$-null mutants, Dlg synaptic levels are substantially and consistently reduced. Costaining with the presynaptic vesicle markers Synaptotagmin and CSP (Fig. 7A,B) shows that mutant NMJ presynaptic morphology and SV levels appear normal, and that the postsynaptic loss of Dlg occurs in the presence of a morphologically normal synapse. The dPak kinase directly in- teracts with Dlg, and binds Dock to direct GluR localization (Albin and Davis 2004). dPak is tightly localized in wild-type embryos to post-synaptic punctae apposing AZ domains, closely resembling the GluR domains, and also strongly concentrated at muscle attachment sites (Fig. 7B). In mtg mutants, dPak localization is strikingly abnormal, and is typically strongly elevated throughout both synaptic and nonsynaptic regions, with nonsynaptic expression greatly obscuring localized synaptic expression (Fig. 7B). Similarly, Dock is concentrated at wild-type NMJs in a pattern resembling Dlg (Fig. 7C), but is grossly mislocalized throughout $\mathrm{mtg}$ mutant muscle, with aberrantly high expression in nonsynaptic regions (Fig. 7C). Finally, dPix is detected at the lowest levels among the PSD proteins examined, but is enriched at NMJ boutons in wild-type terminals (Fig. 7D). dPix synaptic expression is consistently weaker than control in mtg mutants, but without the gross mislocalization characterizing $\mathrm{dPak}$ and Dock expression (Fig. 7D). These results show that loss of MTG disrupts the post-synaptic localization of all the known molecular players regulating GluR localization.

\section{A}
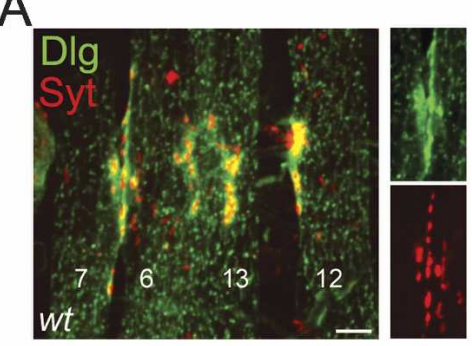

B
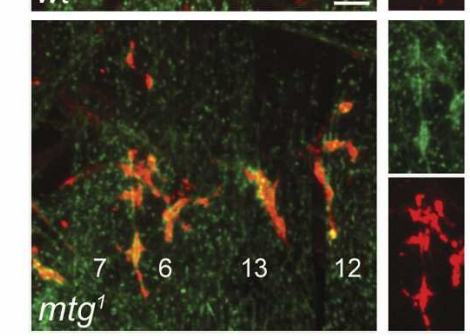

C
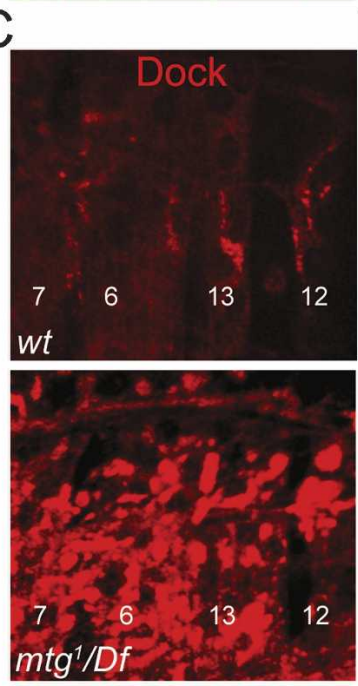
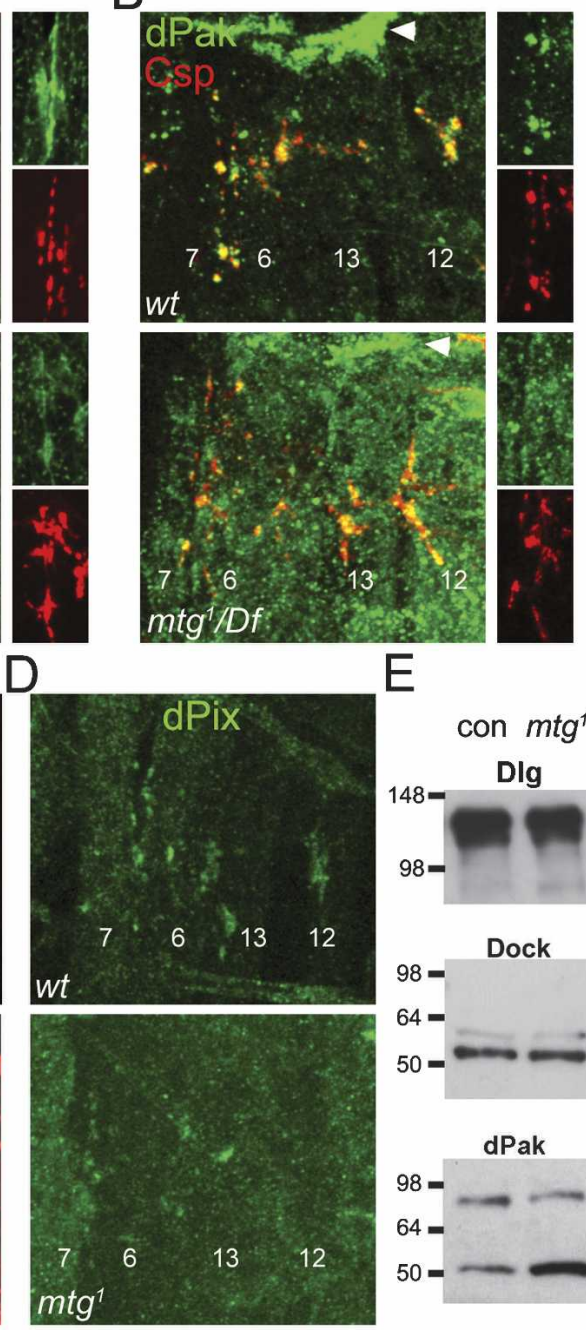

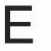

con $m \operatorname{tg}^{1}$

Dlg
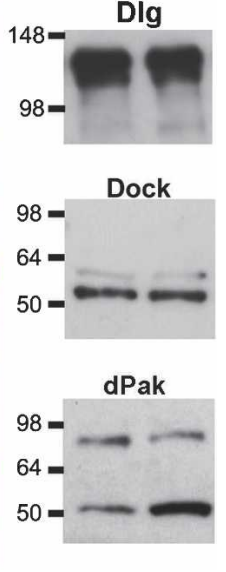

Figure 7. Abnormal expression level and mislocalization of PSD proteins regulating GluR localization at mtg mutant NMJs. (A) Synaptotagmin (Syt, red) and Dlg (green) localization at wild-type (top) and $m t^{1}$ mutant (bottom) embryonic NMJs. The integral presynaptic vesicle Syt protein is distributed normally at $m$ tg mutant synapses. Post-synaptic Dlg is substantially and selectively reduced at mutant NMJ boutons. (Right panels) Dlg and Syt signals are shown individually at NMJ 6/7. Results similar to those shown for $m t^{1}$ were obtained for $m t^{1} / D f(C A 3)$. (B, top) Wildtype embryonic NMJ boutons exhibit punctate postsynaptic dPak (green) localization closely apposing the presynaptic vesicle marker Csp (red). dPak is also strongly concentrated at muscle attachment sites (large arrowhead). (Bottom panel) In $\mathrm{mtg}^{1} / D f(C A 3)$, dPak is not restricted to synaptic punctae, and nonsynaptic levels are grossly elevated. (Right panels) dPak and Csp signals are shown individually at NMJ 6/7. Similar results were obtained for $m t^{1}{ }^{1}$ (C) Dock (Dreadlocks) is concentrated at wild-type embryonic NMJs (top), but grossly and abnormally elevated throughout synaptic and nonsynaptic muscle areas at $\mathrm{mtg}^{1} / D f(C A 3)$ NMJs (bottom). (D, top panel) dPix staining is localized to synaptic domains at wild-type embryonic NMJs. Synaptic dPix level is reduced at $m t g$ mutant NMJs, but is not grossly mislocalized as for dPak and Dock. Bars: $A-D, 5 \mu \mathrm{m}$. (E) Dlg, Dock, and dPak protein levels in Western blots of wild-type (con) and $m t^{1}$ embryonic extracts. In the $m t g$ mutant, Dlg and Dock levels are not detectably altered, but dPak levels (bottom gel) are significantly increased $(n=4)$. 
We therefore next performed Western blot analyses of Dlg, dPak, and Dock protein to determine whether the changes in $\mathrm{mtg}$ tissue localization/distribution is correlated with alterations in overall protein levels. An obvious caveat to these studies is that changes in protein expression levels at synapses, or even within the muscle, may not be detectable at the whole embryo level. Protein extracts from mature (20-22 h) wild-type and $\mathrm{mtg}^{1}$-null mutant embryos were probed with Western blots for each of these proteins (Fig. 7E). Strong positive bands were detected for all proteins, with dPak signal present in two bands. There was no detectable change in either Dlg or Dock protein levels in $\mathrm{mtg}^{1}$ mutants compared with control. In contrast, dPak protein levels were clearly and consistently elevated in $\mathrm{mtg}^{1}$ over control $(n=4)$ (Fig. 7E). These results suggest that the altered post-synaptic expression of Dlg and Dock may represent protein mislocalization, whereas the altered post-synaptic expression of dPak may be caused by both mislocalization and overexpression.

\section{MTG is required presynaptically for post-synaptic differentiation}

The presynaptic neuron is both necessary and sufficient to induce post-synaptic differentiation at the Drosophila NMJ synapse (Broadie and Bate 1993a,b). Our results strongly suggest that MTG is localized within the motor nerve terminal, secreted into the synaptic cleft to bind extracellular GlcNAc, and plays a role in forming/stabilizing the cleft matrix, which induces post-synaptic differentiation. This hypothesis is further supported in that the post-synaptic targeting of the entire dPix-dPak-DLG-Dock pathway regulating GluR domain is disrupted in $\mathrm{mtg}$ mutants. To directly test this hypothesis, we transgenically expressed the UAS-mtg-RNAi construct under the control of ubiquitous, neuronal-specific, and muscle-specific drivers to determine the presynaptic requirement for MTG in regulating this post-synaptic pathway (Fig. 8).

Ubiquitous mtg RNAi expression (UH1-Gal4/UAS$m t g-R N A$ i) significantly reduces embryonic $m t g$ mRNA levels detected by RT-PCR, and results in late second instar lethality (Fig. 8A), indicating a strong hypomorphic $m t g$ condition. Ubiquitous $m t g$ RNAi consistently decreases NMJ synaptic levels of Dlg and GluRs (GluRIIC) (Fig. 8B), as well as dPak and dPix (data not shown), in late second instar larvae. RNAi larval muscle does not display obviously mislocalized or elevated nonsynaptic protein localization, in contrast to the $\mathrm{mtg}^{1} \mathrm{em}$ bryonic mutant. To determine whether this difference in RNAi phenotype severity is developmental, or due to different levels of $m t g$ function, we further assayed postsynaptic protein localization at UH1-GAL4 UAS-mtg RNAi embryonic NMJs. These RNAi embryos also display reduced NMJ expression levels of GluRIIC, dPak, and Dlg compared with controls, but these post-synaptic proteins again are not grossly mislocalized (Supplementary Fig. S3). The RNAi synaptic expression phenotype appears highly similar in embryonic and larval NMJs, but is less severe than for embryonic $\mathrm{mtg}^{1}$ genetic mutants, for which some synaptic proteins are also grossly mislocalized. Although the reason for this difference is unclear, it likely reflects the complete loss of function in the $m \mathrm{tg}^{1}$ mutant compared with the partial loss of function RNAi condition. These results clearly show the role of MTG in post-synaptic development by an independent genetic method, and demonstrate a maintained requirement for MTG in the regulation of the dPix/dPak/ $\mathrm{Dlg} /$ GluR pathway during post-embryonic synaptic development.

To test the prediction that presynaptically secreted MTG is required for post-synaptic differentiation, $\mathrm{mtg}$ RNAi was targeted to the presynaptic neuron under the control of the neuronal-specific elav-Gal4 driver in the $\mathrm{mtg}^{1} /+$ heterozygous background (elav-Gal4/+; UAS$m t g-R N A i / m^{1}$ ) (Fig. $8 \mathrm{C}$ ). The presynaptic RNAi animals show reduced larval and adult viability, though substantial numbers of viable adults survive. Examination of dPix, dPak, Dock, Dlg, and GluRs in the third instar larvae shows that NMJ expression levels of each protein is decreased in parallel and to a comparable degree, compared with driver controls (Fig. 8C). Again, the larval presynaptic loss-of-function phenotype is manifested as a loss of post-synaptic expression level for each post-synaptic protein, rather than protein mislocalization. Heterozygote $\mathrm{mtg}^{1}$ /TM3 synaptic protein staining was not detectably reduced from control /data not shown), indicating the elav; RNAi phenotype is specific to a neuronal loss of function. The severity of the PSD expression phenotypes is comparable for presynaptic RNAi and ubiquitous RNAi larvae (Fig. 8B,C), a result predicted if MTG's requirement is in the presynaptic neuron. In contrast, $m t g$ RNAi expression targeted in post-synaptic muscle (MHC-Gal4/+; UAS-mtg RNAi) had no effect on larval or adult viability, and caused no detectable change in any post-synaptic protein expression at the NMJ (Supplementary Fig. S3). These results demonstrate that only presynaptic MTG is required for the post-synaptic localization of GluRs, and all proteins known to function upstream of GluR localization, and indicate that presynaptically released MTG plays a critical role in inducing post-synaptic assembly during embryonic synaptogenesis, and has a maintained role in post-embryonic synapse maturation.

\section{Discussion}

MTG is required for synaptic cleft matrix formation and post-synaptic assembly

The mind the gap ( $\mathrm{mtg}$ ) gene was isolated in an unbiased forward Drosophila genetic screen for novel mutants blocking functional differentiation of the glutamatergic NMJ synapse. This screen has now revealed numerous novel genes and mechanisms regulating pre- or post-synaptic development (Featherstone et al. 2002, 2005; Rohrbough et al. 2004; Huang et al. 2006), including GluR subunits and genes regulating functional receptor expression (Featherstone et al. 2002, 2005). Loss of $\mathrm{mtg}$ 


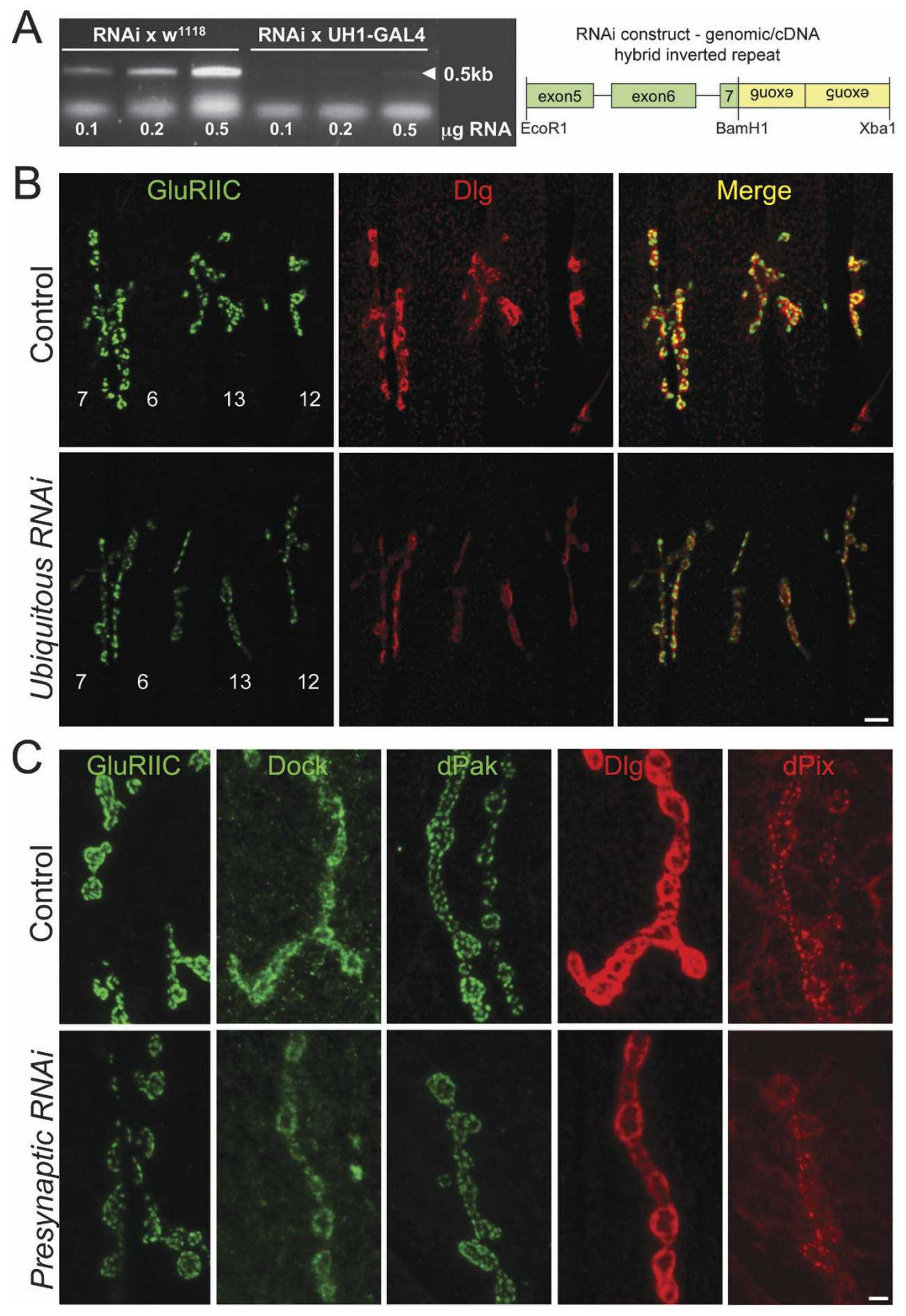

Figure 8. Ubiquitously and presynaptically targeted mtg RNAi similarly impair postsynaptic differentiation of GluR domains. (A, left panel) Embryonic $m t g$ transcript levels are greatly reduced by ubiquitous RNAi expression (UH1 Gal4/UAS mtg RNAi). Right panel depicts the RNAi construct. (B) Synaptic GluRIIC (green) and Dlg (red) levels are decreased by ubiquitous mtg RNAi. Images show NMJs $(7 / 6,13,12)$ in a second instar driver control (UH1 Gal4/+, top) and mtg RNAi larva (UH1 Gal4/UAS mtg RNAi, bottom). Bar, 5 um. (C) GluRIIC, Dock, dPak, Dlg, and dPix synaptic localization are all similarly impaired by targeted presynaptic knockdown of $m t g$. Panels show third instar presynaptic driver control (elav Gal4) $+, t o p)$, and $\mathrm{mtg}^{1} /+$ larvae expressing neuronally targeted $m t g$ RNAi expression (elav Gal4; $\mathrm{mtg}^{1} / \mathrm{UAS}$ mtg RNAi; bottom). Synaptic expression levels of all PSD proteins examined are reduced to a similar degree by ubiquitous and targeted presynaptic $\mathrm{mtg}$ RNAi larvae. Bar, $2 \mu \mathrm{m}$. results in a severe, $\sim 80 \%$ loss of GluR function at the NMJ. Notably, this phenotype represents the most severe mutant GluR impairment ever reported, with the exception of genetic mutants for the requisite GluR subunits (IIC-IIE) themselves (Featherstone et al. 2005; Qin et al. 2005). MTG is expressed neuronally and localized synaptically, contains a well-conserved secretory signal sequence, and is secreted and binds GlcNAc in vitro. These findings support the working hypothesis that MTG is secreted into the synaptic cleft to bind ECM glycosaminoglycans (GAG) or proteoglycans (PG) during glutamatergic synaptogenesis.

The $m t g$ developmental expression profile closely parallels the timing of NMJ synapse formation and functional differentiation. Expression increases sharply with initial nerve-muscle contact (12-13 h after fertilization), and peaks at $16-17 \mathrm{~h}$, correlating with post-synaptic GluR domain assembly $(15-17 \mathrm{~h})$ (Broadie and Bate 1993c). MTG protein is concentrated in embryonic neurons, and becomes increasingly localized with development to NMJ synaptic domains, and to other cell adhesion sites such as muscle attachment sites, where many synaptic signaling (Pix, Pak, integrins) and scaffold proteins (Dlg) are colocalized. MTG is found in the presynaptic terminal and post-synaptic SSR, clearly detected within the extracellular synaptic cleft domain, consistent with presynaptic secretion as well as a transsynaptic regulatory role. In the absence of MTG, post-synaptic GluR puncta apposed to the presynaptic terminal are lost, and GluRs are dispersed in the nonsynaptic mem- 
brane, resulting in profound functional transmission loss. The mislocalized GluRs appear nonfunctional based on the muscle response to exogenously applied glutamate, which demonstrates a dramatic overall loss of functional cell surface GluRs. All PSD proteins known to act in the upstream GluR regulatory pathways (dPix, dPak, Dlg, Dock) (Parnas et al. 2001; Albin and Davis 2004) are severely reduced or mislocalized in $\mathrm{mtg}$ mutants, indicating that MTG acts at an upstream organizing step required to establish this cascade of postsynaptic interactions. The loss of synaptic cleft matrix material at $\mathrm{mtg}$ mutant synapses indicates first, that MTG is required for this signaling domain to be established, and second, suggests that this domain has an important inductive, instructive role in post-synaptic assembly.

We have not yet succeeded in genetically rescuing the $m t g$ mutant with a wild-type copy of the $m t g$ gene. Since $m t g$ is present at low overall levels during much of development, it is likely that $m t g$ expression timing and/or level must be precisely regulated for normal protein function and animal viability. Transgenic rescue with tissue-targeted Gal4-driven mtg expression may therefore result in a deleterious overexpression condition. Transgenically expressed mtg RNAi, however, phenocopies $m t g$ mutant phenotypes. Ubiquitous $m t g$ RNAi causes early lethality and defective post-synaptic assembly, with reduced synaptic localization of GluRs and other upstream regulatory proteins. These phenotypes are more severe in the $m t^{1}$ mutant, which exhibits lethality at the hatching stage, and also nonsynaptic mislocalization of post-synaptic proteins. Therefore, the findings are consistent with the expected effects of RNAi as a partial loss-of-function condition. Most conclusively, targeted RNAi knockdown of MTG in the presynaptic neuron impairs post-synaptic differentiation and the assembly of GluR domains with a similar severity to the ubiquitous RNAi condition. In contrast, muscle-targeted $m t g$ RNAi has no detectable effect on movement or animal viability, and does not cause any detectable synaptic impairment or defects in post-synaptic assembly. Taken together, these results support the identity of the $m t g$ gene and suggest that presynaptically secreted MTG protein is required for post-synaptic development. We conclude that MTG is a critical element in the presynaptic inductive mechanism.

\section{MTG is a secreted protein predicted to bind extracellular synaptic proteoglycans}

MTG has a cysteine-rich carbohydrate-binding module (CBM) with homology with ChtBDs found in peritrophic matrix proteins, lectins, and other known ECM proteins. This domain contains six conserved cysteines predicted to form three disulfide bridges within a $\beta$-folded carbohydrate-binding structure that binds GlcNAc moieties. Lectins that specifically bind GlcNAc (WGA) and GalNAc (DBA, VVA) are commonly used synaptic cleft or post-synaptic markers at the vertebrate NMJ (Martin 2003b). Here we confirm that WGA-binding targets are localized to Drosophila NMJ boutons, and that extracted MTG protein binds GlcNAc in vitro, suggesting that MTG recognizes GlcNAc-containing target(s) in the synaptic cleft. Drosophila S2 cells transformed with MTGGFP secrete the protein, which accumulates both on the outer surface of the cells and in the medium, supporting its extracellular localization. However, we have not yet succeeded in replicating the GlcNAc binding with purified MTG protein, the ideal experiment to confirm and further probe the binding specificity. GlcNAc-containing carbohydrate and GAG scaffolds (e.g., chitin, hyaluronic acid [HA], heparin) and PG (e.g., heparin sulfate, chondroitin sulfate) are components of neuronal and muscle ECM, and concentrated within the specialized synaptic cleft matrix at the NMJ and other synapses in multiple species (Martin 2003b; Dityatev et al. 2006). It was recently shown that loss of GlcNAc transferase alters In Drosophila NMJ synaptic structure, function, and locomotory behavior (Haines and Stewart 2007), independently demonstrating GlcNAc-mediated interactions have roles in synaptic maturation.

MTG does not share significant overall whole-sequence homology with an identified vertebrate protein. It is increasingly recognized that many Drosophila proteins are conserved at a structural level to serve identical functions with mammalian functional homologs; among many examples are neurotrophin-like proteins and their receptors (Wilson et al. 1993; van Kesteren et al. 1998; Yuan and Ganetzky 1999; Davoli et al. 2002) and olfactory receptors (Matsunami and Amrein 2003; Benton 2006). Several vertebrate protein families contain cysteine-rich domains with predicted structural homology with MTG, including the TGF- $\beta$, GPH, PDGF, and NGF growth factor families (McDonald and Hendrickson 1993; Sun and Davies 1995; Hearn and Gomme 2000; Vitt et al. 2001). CDM/ChtBD-related domains are common in other secreted protein families, including knottins, mucins and lectins. These domains contain six to 10 cysteine residues predicted to form disulfide bridges, which mediate homo- or heterodimer formation, carbohydrate binding, and extracellular ligand-target/receptor interactions (Vitt et al. 2001; Boraston et al. 2004; Desnoyers 2004). Laminin integrin ligands contain the structurally related type-1 EGF domain, which is a site of receptor recognition and ECM binding. The consistent extracellular function of these related disulfide-forming protein domains is to mediate ECM protein interactions and ligand-receptor intercellular signaling. We propose a similar function for MTG in organizing the synaptic cleft matrix and mediating transsynaptic signaling critical for synaptogenesis.

\section{Potential MTG function within the specialized synaptic cleft matrix domain}

Null mtg mutants show a reduction or complete absence of electron-dense synaptic matrix, suggesting a loss or gross disorganization of multiple synaptic ECM components and binding proteins. To our knowledge, this is the first such cleft phenotype reported for a functional syn- 
aptic mutant. Vertebrate neuronal and perisynaptic ECM consists of a GAG scaffold matrix (e.g., heparin sulfate, chondroitin sulfate, HA), numerous bound proteins, laminins, and transmembrane molecules/receptors interacting with the matrix, including NCAM family proteins and integrins (Dityatev et al. 2006; Viapiano and Matthews 2006). Much less is known, however, about the mechanisms linking the synaptic cleft matrix structural and signaling environment to post-synaptic assembly. The regulation of acetylcholine receptor (AChR) expression/localization at vertebrate NMJs by the agrinagrin receptor (MusK)-rapsyn pathway provides an obvious framework for comparison (Sanes and Lichtman 2001), although the role of agrin in post-synaptic receptor maintenance versus domain assembly has recently been redefined (Misgeld et al. 2005; Kummer et al. 2006). The vertebrate cholinergic NMJ is concentrated in GlcNAc- and GalNAc-containing GAG and PG, in particular secreted (agrin, perlecan) and transmembrane (syndecan) heparin sulfate proteoglycans (HSPG); laminins, which act as integrin ligands and interact directly with other membrane proteins including $\mathrm{Ca}^{2+}$ channels (Nishimune et al. 2004); and ECM transmembrane receptors, including receptor tyrosine kinases (RTK) and integrins, activated by binding of ECM ligands (Sanes and Lichtman 2001; Martin 2003b; Dityatev et al. 2006; Viapiano and Matthews 2006). Integrins represent an appealing ECM receptor-mediated link to Pix-Pak pathway activation in vertebrates, and hippocampal synapse formation and plasticity in the hippocampus (Zhang et al. 2003, 2005; Webb et al. 2007).

Three integrin receptor subtypes ( $\alpha \mathrm{PS} 1 / \beta \mathrm{PS}, \alpha \mathrm{PS} 2 /$ $\beta P S, \alpha P S 3 / \beta P S)$ localize to the Drosophila NMJ, and regulate synaptic structural development and functional transmission properties, including activity-dependent plasticity (Prokop et al. 1998; Beumer et al. 1999, 2002; Rohrbough et al. 2000). Integrins, RGD domain-containing laminins (Prokop et al. 1998), and the secreted synaptic cleft protein Hikaru Genki (Hoshino et al. 1996, 1999) regulate synapse formation and ultrastructure. More recently, two synaptic HSPGs, Syndecan (Sdc) and Dallylike (Dlp), were shown to localize to the NMJ and regulate presynaptic terminal growth and AZ formation, respectively (Johnson et al. 2006). The receptor tyrosine phosphatase dLAR is a receptor for both Sdc and Dlp and interacts with these ligands via their GAG chains (Fox and Zinn 2005). Drosophila dystrophin has also recently been shown to localize post-synaptically (van der Plas et al. 2006), and form a synaptic glycoprotein complex with extracellular dystroglycan (Dekkers et al. 2004). Surprisingly, Drosophila dystrophin regulates presynaptic properties, but not post-synaptic GluR expression (van der Plas et al. 2006). Our studies do not suggest that MTG is a major structural component of the synaptic cleft matrix, but rather that MTG has a necessary role in organizing the broader structure and transsynaptic signaling capabilities of the synaptic cleft ECM. If this hypothesis is correct, the severity of the mtg mutant phenotypes may be due to a disruption of multiple transsynaptic signaling pathways.

\section{Models for MTG synaptic function}

Our findings suggest that interactions between MTG and its GAG/PG-binding partner(s) in the synaptic cleft matrix are linked to the activation and localization of PSD signaling pathways. Protein localization/binding studies and three-dimensional structural models suggest that the cleft domain is a dense GAG scaffold extensively linked by secreted matrix PG, including chondroitin sulfate PG (tenascins, lecticans, phosphacans), and HSPGs (perlecan, $\beta$-glycans, agrins), as well as by transmembrane HSPGs (syndecans, systroglycans), GPIlinked membrane-bound proteins (glypicans), NCAMs, and integrins (Ohtsuka et al. 2000; Yamaguchi 2000; Martin 2003a; Viapiano and Matthews 2006). This matrix could act in part to sterically trap or limit lateral movement of transmembrane proteins to maintain them in the synapse. Such a mechanism could preferentially or selectively serve to localize a key upstream signaling molecule, such as dPix, thus localizing the downstream dPak-Dlg-Dock cascade necessary for GluR aggregation. Similarly, the synaptic matrix may directly inhibit GluR lateral membrane diffusion, effectively ensnaring GluRs at post-synaptic sites. In the absence of the matrix, GluR dispersal could prevent accumulation of functional puncta. Alternatively, MTG may be more directly involved in forming a synaptic cleft signaling environment that allows signal molecules and/or receptors to be properly presented or anchored. It is also possible that MTG may function directly as an inductive signal by binding to an unidentified receptor. For example, synaptic localization of Dock requires its interaction with an unidentified SH2 domain-containing RTK (Albin and Davis 2004), but the identity of this RTK or its effectors is unknown.

MTG is required for the post-synaptic localization/activation of the dPix-dPak-Dock-Dlg pathways. dPix binds to and is required to localize dPak; dpix and dpak mutants equally reduce synaptic Dlg level, and essentially eliminate formation of the post-synaptic SSR domain where these proteins reside (Parnas et al. 2001; Albin and Davis 2004). A dPak-Dock interaction is required to regulate synaptic levels of A-class GluRs (Albin and Davis 2004). The GluR phenotypes of $d p i x$, $d p a k$, and dock mutants are all similar, reducing A-class GluRs by $\sim 50 \%$. These mutants are nevertheless viable through larval development in the near absence of dPix, dPak, or Dock, and NMJ synaptic transmission strength in basal evoked recordings is normal, due in large part to compensatory mechanisms leading to increased transmitter release (Albin and Davis 2004). In studies in mature larvae, dpix, dpak, and dock mutations cause decreased expression level of post-synaptic proteins (Parnas et al. 2001; Albin and Davis 2004), without the dramatic mislocalization phenotypes characteristic of $m t g$ functional null mutants at the embryonic NMJ. However, we show that strong MTG knockdown by RNAi in embryos and larvae causes a loss of post-synaptic protein levels that appears comparable with the phenotype in $d$ pix and dpak mutant larvae (Parnas et al. 2001; Albin and Davis 
2004). These findings suggest that the greater severity of the $\mathrm{mtg}^{1}$ mutant phenotype is likely due to a more severe loss of MTG function in the null condition, rather than simply due to a developmental disruption during the embryonic synaptogenesis period. Alternatively, since loss of MTG affects synaptic localization of both dPak and Dock individually, the full loss-of-function mtg phenotype severity may result from an additive block of several branches of the intertwined post-synaptic differentiation pathways.

\section{Future directions}

Our hypothesis is that presynaptically secreted MTG establishes the synaptic cleft matrix signaling environment required for transsynaptic ligand-receptor pathways inducing post-synaptic differentiation. Several questions must next be addressed to test this hypothesis. One goal is to thoroughly test the GlcNAc binding specificity of MTG using purified protein and competitive binding assays. The future task will be to identify GlcNAc-containing GAG- or PG-binding target(s) of MTG resident in the synaptic cleft. Synaptic labeling with carbohydrate-specific lectins and matrix-specific antibodies (Martin 2003b), and genetically/pharmacologically altering synaptic protein glycosylation (Haines and Stewart 2007), will identify predicted glycosylated matrix components and potential targets. Site-directed mutational analysis of the key disulfide-forming cysteines in the GlcNAc-binding domain will allow us to test this domain's role in MTG function. Another major goal will be to test other known transsynaptic signal/ receptor pathways include Wg/Frz, Gbb/Wit, Syndecan/ dLAR, DG/Dystrophin and integrin ligands (Hig, laminin)/integrins. Future studies will test whether these pathway components are lost/mislocalized in $\mathrm{mtg}$ mutants, as predicted by our model. Genetic interactions should exist between established signaling pathways and MTG, which can be tested in double mutant combinations to determine whether $m$ tg phenotypes result from the additive disruption of multiple signaling pathways, as predicted. Finally, MTG may itself be an anterograde transsynaptic signaling molecule acting through a postsynaptic receptor. We therefore will also pursue the potential receptor identities and assay possible signal-receptor interaction mechanisms during synaptogenesis.

\section{Materials and methods}

\section{Drosophila genetics}

The EMS screen was performed on an isogenized rucuca $(r u, h$, th, st, $c u, s r, e, c a$ ) third chromosome (Featherstone et al. 2000). For mapping and functional analyses, deficiencies in cytological region 84/85 were obtained from the 3rd Chromosome Deficiency Kit (Bloomington Drosophila Stock Center). The left and right limits of $m t g$ were determined by complementation with $D f(3 R) \mathrm{dsx} 11$ (84D8-84D9;85A1-85A2) and $D f(3 R) \mathrm{p}-\mathrm{XT} 103$ (85A2;85C1-85C2). Df(3R)CA3 (84F2;85A6-7) fails to complement $\mathrm{mtg}^{1}$. The $\mathrm{mtg}^{1}$ allele was outcrossed to wild-type Or-
egon-R (OR) to recombine away the majority of the rucuca chromosome, resulting in st, $\mathrm{mtg}^{1}$, and $\mathrm{cu}$. OR, $\mathrm{mtg}^{1} / \mathrm{t}$, and $D f(C A 3) /+$ were used as genetic controls. P-element allele $\mathrm{P}\left[\mathrm{ry}^{+\mathrm{t} 7.2}=\mathrm{RP} 49\right] \mathrm{A} 3 \mathrm{ry}^{506}$ was obtained from Bloomington Stock Center. P-element allele $\mathrm{y}^{1}, \mathrm{w}^{1}$; P[1acW]1(3)SO84910, obtained from the Szeged Drosophila Stock Center (Deak et al. 1997), was used in a local hop to generate small deletion alleles, $\mathrm{mtg}^{P 4}$ and $m t^{P 5}$, and three precise excision lines. These control lines are viable to adulthood and completely complement $\mathrm{mtg}^{1}$. Gal4 driver lines used included elav gal4 (P[GawB]elavC $\left.{ }^{155}\right)$ UH1 gal4 (P[GAL4-da.G32]UH1), and MHC gal4 (P[GAL4-Mhc.W]MHC-82). GFP balancer lines used included TM3, $\mathrm{P}$ [ActGFP]JMR2, $\mathrm{Ser}^{1}$ and TM3, P[GAL4-Kr.C]DC2, P[UASGFP.S65T]DC10, $\mathrm{Sb}^{1}$.

\section{Molecular techniques}

Molecular mapping was performed by inverse PCR $\left(\mathrm{mtg}^{\mathrm{P} 2}\right)$ and plasmid rescue $\left(m \mathrm{tg}^{P 3}\right)$. Genomic DNA was isolated, digested, ligated, and used as a template for PCR. Upstream flanking genomic DNA was recovered using Sall to cut, and primers Plac1 (5'-CACCCAAGGCTCTGCTCCCACAAT-3') and Plac4 (5'-ACTGTGCGTTAGGTCCTGTTCATTGTT- $\left.{ }^{\prime}\right)$ to amplify. Downstream flanking genomic DNA was recovered using Sau3A1 and Pryl (5'-CCTTAGCATGTCCGTGGGGTTTGA AT-3') and Pry4 (5'-CAATCATATCGCTGTCTCACTCA-3'). For plasmid rescue, genomic DNA was digested with BamH1, ligated, and transformed into ElectroMAX DH10B Escherichia coli. Plasmids were obtained from ampicillin-resistant colonies, and sequenced using primer $5^{\prime} 2\left(5^{\prime}\right.$-TCAACAAGCAAACGTG CACTG-3'), yielding genomic sequence downstream from the P-element, and $37 \mathrm{nt}$ downstream from the $\mathrm{mtg}^{P 2}$ insertion site. To confirm the upstream genomic flanking region, P-element primer 5'Y (5'-CACCTCTGACTTGAGCGTCG-3') and primer mtg3F (5'-CTTACCGCGATTGCAACTTC-3'), 81 nt upstream of the insertion site, were used to PCR from $\mathrm{mtg}^{P 3}$ genomic DNA. Genomic DNA from homozygous $\mathrm{mtg}^{1}$ embryos and parental rucuca embryos was PCR-amplified and sequenced. The genes upstream of the P-element insertion site were sequenced from 3R:4069516 to 3R:4076437 and no mutation was found. The next downstream gene (CG7549) was subsequently sequenced from 3R:4082377 to 3R:4086202, which is $292 \mathrm{nt}$ downstream from the final stop codon in exon 8. A C-T substitution in the fifth exon caused a Q134STOP mutation, leading to truncation of the protein $20 \%$ of full length. To identify $\mathrm{mtg}$ exons, RACE was performed using the SMART RACE cDNA Amplification Kit (Clonetech Laboratories). Total RNA was isolated from 200-300 wild-type embryos (17-19 h) in TRI ReagentR (Ambion), and DNased using Turbo DNA-free. cDNA was made using oligo dT primer and $\mathrm{RT}$ reagents from the SMART RACE kit. RACE fragments were amplified using kit primers at the $5^{\prime}$ end, and a $m t g$ exon 6 primer-SR60B (5'-GT GTTCGGCCTTTAGCTGCTGCTCCCGG-3'). The product was additionally amplified by nested PCR, using SR60B and a nesting primer from the SMART RACE kit. Fragments were isolated and cloned into pGEM. Clones were sequenced (Vanderbilt University Sequencing Core) and analyzed using Sequencher.

$m t g$ RNA developmental expression was analyzed in staged embryos, larvae, and pupae collected at specified ages, following timed egg lays done on apple juice plates. Homozygous $m \operatorname{tg}^{P 2}$ and $D f(C A 3)$ mutant embryos, and UAS-mtg RNAi/UH1-gal4 embryos aged $16-20 \mathrm{~h}$ were each collected to assay $m$ tg RNA level. For these experiments, tissue was ground in TRI Reagent (Ambion), vortexed with chloroform, and centrifuged to isolate the RNA in the aqueous phase. RNA was precipitated with 
isopropanol, resuspended in RNase-free water, and measured by spectrophotometer. Five micrograms were treated with DNase (TURBO DNA-free, Ambion). RNA concentrations were measured again and either $0.05,0.1$, and $0.25 \mu \mathrm{g}$ (for the time line) or $0.1,0.2$, and $0.5 \mu \mathrm{g}$ (for the RNAi) was used in RT-PCR reactions using the Titan One-Tube RT-PCR kit (Roche) and primers to $m t g$ exons 4 and 6 to obtain a 458-nt band (mtg forward primer, 5'-TTGGTGGGCGTACTTCCATC-3'; reverse primer, 5'-TTTTCACGTGGCCAACCCG-3'). Control primers to PFK mRNA were forward primer, 5'-GTCTGAACATCGTGATT GTGG-3', and reverse primer, 5'-GCAGTGTGCGTTTGGT AC-3', giving rise to a 675-nt band. Product was measured using Image to outline and quantify gel band mean intensity obtained with the $0.05-\mu g$ template amount.

\section{Bioinformatics}

Sequence data were analyzed using Sequencher (GeneCodes) and genes contained within the sequence were identified using FlyBase and GeneBrowse at FlyBase (Grumbling and Strelets 2006). Sequences were identified using BLAST and BLASTP at the NCBI site (http://www.ncbi.nlm.nih.gov). Protein domain and structural comparisons were made within the following sites: InterProScan (http://www.ebi.ac.uk/InterProScan), ProDom (http://prodom.prabi.fr/prodom/current/html/form.php), ScanProSite (http://us.expasy.org/tools/scanprosite), and Knottin database (http://knottin.cbs.cnrs.fr). The signal peptide was identified by the SignalP server at the Center for Biological Sequence Analysis (http://www.cbs.dtu.dk/services/SignalP). The disorder plot was generated using the DISOPRED2 Disorder Prediction Server (http://bioinf.cs.ucl.ac.uk/disopred). Clustal alignment of GlcNAc-binding domains was obtained from searches for conserved domains in MTG at the NCBI Web site (http://www.ncbi.nlm.nih.gov/Structure/cdd/cdd.shtml). The predicted CBM14 domain was automatically aligned by Clustal with a variety of CBM14-containing proteins. We then aligned the MTG CBM14, using ClustalW (http://www.ebi.ac.uk/clustalw).

Expression of MTG-GFP recombinant protein in S2 (D.mel-2) cells

A full-length cDNA obtained by RACE cloning, comprising all eight exons of $\mathrm{mtg}$, was cloned into pMT-tauGFP from the Drosophila Genomics Resource Center (Bunch et al. 1988). The pMT vector was digested with EcoR1 and BamH1 to remove the tau gene, and $m t g$ cDNA was ligated in to make an in-frame GFP fusion. Drosophila D.mel-2 cells (Invitrogen) were grown at $27^{\circ} \mathrm{C}$ on glass coverslips in Drosophila-SFM (serum-free medium; Invitrogen) supplemented with $16.5 \mathrm{mM}$ L-glutamine. Cells were transfected in six-well plates with $2 \mu \mathrm{g}$ of pMTmtgGFP or pMT-tauGFP or no vector (uninduced), using $10 \mu \mathrm{L}$ cellfectin per millilter (Invitrogen). Expression was induced after $24 \mathrm{~h}$ with $0.7-1.4 \mathrm{mM} \mathrm{CuSO}_{4}$. Cells were fixed for imaging 48-72 $\mathrm{h}$ after induction. For Western analysis of protein expression and secretion, cell-conditioned culture medium (supernatant) from mtg-GFP- and tau-GFP-expressing cultures was collected using a wide-mouthed pipette, centrifuged to remove all cells and cell debris, and concentrated $\sim 10$-fold using Microcon YM-30 centrifugal filter devices. Cells were then removed and harvested from the dishes in PBS using a wide-mouthed pipette, collected by centrifugation, and homogenized in PBS buffer $\mathrm{pH}$ 7.4) containing $1 \%$ igepal, $2.5 \mathrm{mM}$ EGTA, and Roche miniprotease inhibitor. Lysate was centrifuged to remove insoluble material. Approximately $100 \mu \mathrm{g}$ of protein were analyzed by PAGE using $5 \% \beta$-mercaptoethanol. The gel was transferred to a ni- trocellulose membrane and probed using anti-GFP antibody (Abcam).

\section{RNAi constructs and transgenic lines}

The UAS-mtg RNAi construct was made from genomic DNA, using primers to exons 5 and 7 (mtgex5Eco, $5^{\prime}$-TCTGAATTC GGTCAATCCACCCGTGCAAC-3'; mtgex7Bam, 5'-CTTTAG GGGGATCCATTACCTAATATAAATTAGTAAAC- $3^{\prime}$ ), and from cDNA by RT-PCR using primers to exons 5 and 6 (mtgex5Xba, 5'-CCATCTAGAGGTCAATCCACCCGTGCAA C-3'; mtgex6Bam, 5'-ATTGGATCCCTTGGACACCTTGTGC TCCGC-3'). DNA was ligated as an inverted repeat genomic/ cDNA hybrid, and ligated into the Drosophila expression vector pUAST. Transgenic lines were established using standard approaches, and the following genetic combinations were used to analyze RNAi knockdown lethality and synaptic phenotypes (Genetics Services, Inc.): elav-gal4/+ or Y; $\mathrm{mtg}^{1} / \mathrm{UAS}-m \mathrm{tg}$ RNAi, UH1-gal4/UAS-mtg RNAi, UH1-gal4, $\mathrm{mtg}^{1} / \mathrm{UAS}-\mathrm{m} t \mathrm{~g}$ RNAi, MHC-Gal4/+; UAS-mtg RNAi/+.

\section{Western blot analyses and GlcNAc-binding assays}

Antibodies were generated against three peptide sequences in the MTG protein: (1) two rabbit sera (1A and 1B, Washington Biotechnology, Inc.), against GLYADTDLGCMVFHVCALTD DGMV, located within the predicted GlcNAc-binding domain; (2) two rabbit sera (2A and 2B, Washington Biotechnology, Inc.), against EQRSMPKEDHEHVVPAEAEQQLSN from the C terminus; and (3) guinea pig serum (52, Open Biosystems) against peptide YLQFEEPKFDLKD, located between the Gln-rich and Thr-rich domains. For GlcNAc-binding experiments, we adapted reported methods (Kitamura et al. 2005). Two-hundred wild-type or homozygous $\mathrm{Df}(3 \mathrm{R}) \mathrm{CA} 3$ embryos were selected at $\sim 16-20 \mathrm{~h}$ of development, frozen at $-80^{\circ} \mathrm{C}$, and ground in lysis buffer (PBS at $\mathrm{pH} 7.2$, containing $1.54 \mathrm{mM} \mathrm{K}^{+}, 1 \%$ igepal, 0.25 mM EGTA, $1 \times$ Roche Complete miniprotease inhibitor). Lysate was centrifuged, and the pellet was incubated with GlcNAcAgarose beads (Sigma) in lysis buffer for $2 \mathrm{~h}$ at room temperature. The beads were then centrifuged to remove lysate, and washed three times in PBS (pH 7.2). Half of the washed beads were kept at $-80^{\circ} \mathrm{C}$, and the remainder were incubated in 20 mM N,N'-diacetylchitobiose overnight at $4^{\circ} \mathrm{C}$ to elute GlcNAcbound proteins. The beads and eluate were separated by centrifugation. Total lysate, washed beads, and eluate were boiled in NuPAGER LDS sample buffer (Invitrogen) and analyzed by SDS-PAGE. Gels were either stained for total protein with NOVEX stainer B or Colloidal Blue (Invitrogen), or transferred to PROTRAN membrane (Perkin-Elmer), blocked with Odyssey blocking buffer (LI-COR Biosciences), probed with anti-MTG 52, and visualized using IRDye800-conjugated anti-guinea pig (Rockland) with an Odyssey scanner. For deglycosylation, total lysate, bead-bound, and eluate protein fractions were each deglycosylated prior to SDS-PAGE using the Enzymatic CarboRelease Kit (QA-Bio), which removes all N-linked oligosaccharides and many O-linked oligosaccharides.

For Western blots of post-synaptic proteins, 50 OR (control) and $50 \mathrm{mtg}^{1} / \mathrm{mtg}^{1}$ embryos staged at 20-22 $\mathrm{h}$ were collected, frozen in liquid nitrogen, and ground in lysis buffer $100 \mathrm{mM}$ $\mathrm{KCl}, 5 \mathrm{mM} \mathrm{MgCl}_{2}, 10 \mathrm{mM}$ HEPES, 0.5\% igepal, $2.5 \mathrm{mM}$ EGTA, $2 \%$ Sigma Protease Inhibitor cocktail at $\mathrm{pH}$ 7.0). Lysate was cleared by centrifugation, and the supernatant was added to an equal volume of Laemmli buffer with $0.2 \mathrm{M}$ dithiothreitol, boiled, loaded in triplicate on $4 \%-20 \%$ NuPAGE bis-tris polyacrylamide gels (Invitrogen), and run in MES SDS buffer (Invitrogen). Proteins were transferred to PROTRAN nitrocellulose 
membranes. Anti-Dlg (Mab4F3) was used at 1/4000, anti-dPak at $1 / 2000$, and anti-Dock at $1 / 1000$. Secondary detection was with HRP-conjugated anti-mouse (Dlg) or anti-rabbit (dPak and Dock), and Supersignal West Dura Peroxidase substrate, imaged on Kodak film.

\section{Immunohistology}

Immunocytochemistry of mature control and mutant embryos and larvae was carried out as described previously (Featherstone et al. 2002; Rohrbough et al. 2004). In all experiments, control and mutant animals were collected in parallel and dissected, processed, and imaged on the same coverslips to allow valid comparison of staining features. Unhatched (20-22 h) embryos were screened and dissected as described below. Larvae were examined at either late second or late third instar stages. Dissected preparations were fixed for 15-30 min in Bouins (picric acid) fixative, washed for $>1 \mathrm{~h}$ in PBS-TX, and stained with primary antibody either overnight at $4^{\circ} \mathrm{C}$, or for $2 \mathrm{~h}$ at room temperature. Central neurons, peripheral axons, and presynaptic NMJ terminals were visualized with Texas Red-conjugated anti-HRP (1:200, Molecular Probes). Presynaptic vesicle staining was examined using antibodies against Synaptotagmin I (rabbit, 1:500) and CSP (mouse, 1:500). GluR clusters were visualized with rabbit anti-GluRIIC (1:500, embryo; 1:2000, larva) and anti-GluRIID (1:500). Post-synaptic density protein staining was visualized by mouse anti-DLG (1:500, Iowa Hybridoma Bank), mouse anti-dPix (1:20 to 1:100), rabbit anti-dPak (1:500), and rabbit anti-Dock (1:500). Primary antibody staining was visualized with Alexa-conjugated secondary probes (1:400 to 1:500, $2 \mathrm{~h}$ at room temperature; Molecular Probes). Cultured S2 cells adhered to glass cover slips were fixed for 10-15 h in $4 \%$ paraformaldehyde in serum-free S2 medium. Slips containing cells were subsequently processed and stained in either detergent-containing $(0.5 \%$ Triton $\mathrm{X})$ or detergent-free PBS. Slips were stained with anti-GFP primary (rabbit, 1:1000) and Alexa 568 anti-rabbit secondary. Vectashield was used as the imaging medium for all fluorescence microscopy. Confocally scanned images of the CNS, neuromusculature, NMJs, and stained S2 cells were acquired on a Zeiss 510 confocal microscope, using Zeiss LSM software and either $40 \times$ or $63 \times$ oil objectives. Confocal sections and Z-series projections were created and exported using LSM image examiner. Control and mutant images were processed in parallel with Adobe Photoshop software.

\section{Electrophysiology}

Staged embryos at the hatching stage $(\sim 22 \mathrm{~h})$ or newly hatched larvae were collected from agar plates, dechorionated in bleach, and washed in $\mathrm{dH}_{2} \mathrm{O}$ as described previously (Broadie and Bate 1993c; Rohrbough et al. 2004). Briefly, homozygous mutants were distinguished from balanced siblings by GFP balancer expression (act-GFP or Kr-GFP). Embryos were transferred to Roger's recording saline $\left(135 \mathrm{mM} \mathrm{NaCl}, 5 \mathrm{mM} \mathrm{KCl}, 1.8 \mathrm{mM} \mathrm{CaCl}_{2}\right.$, $4 \mathrm{mM} \mathrm{MgCl}{ }_{2}, 5 \mathrm{mM}$ TES, $75 \mathrm{mM}$ sucrose, $2 \mathrm{mM} \mathrm{NaOH}$ at $\mathrm{pH}$ 7.2), manually removed from the vitelline membrane, secured at the head and tail to sylgard-coated coverslips using surgical histoacryl glue, dissected open dorsally, and glued flat. Preparations were exposed to collagenase $(1.0 \mathrm{mg} / \mathrm{mL}$, Sigma type IV) in $0.2 \mathrm{mM} \mathrm{Ca}^{2+}$-containing saline for 1-2 min and washed with normal bath recording saline. Whole-cell patch clamp recordings were made from muscle 6 in anterior abdominal segments (A2-A4), at a holding potential of $-60 \mathrm{mV}$. EJCs were evoked by segmental nerve stimulation using a glass suction electrode. Spontaneous miniature EJCs were recorded in $0.5 \mathrm{mM} \mathrm{Ca}^{2+}$. containing saline, in the presence of $0.2 \mu \mathrm{g} / \mathrm{mL}$ TTX. Post-syn- aptic glutamate responses were elicited by two methods: pressure ejection from a patch pipette containing $1 \mathrm{mM}$ L-glutamate in recording saline (2-4 psi, 100- to $200-\mathrm{msec}$ puff) positioned $50-100 \mu \mathrm{m}$ from the NMJ, or by iontophoretic application (50V$60 \mathrm{~V}, 2-5 \mathrm{msec}$ ) from sharp microelectrodes containing $100 \mathrm{mM}$ L-glutamate (in $\mathrm{dH}_{2} \mathrm{O}$ at $\mathrm{pH} 9-10$ ), positioned directly between muscles 6 and 7 NMJ (Rohrbough et al. 2004). Pressure-ejected glutamate encompassed the entire muscle cell including the NMJ. Iontophoretic glutamate application generated larger, briefer glutamate responses with highly reproducible peak amplitudes and $<500$ msec duration, presumably due to more rapid and effective activation of synaptic GluRs, and was used in the majority of experiments to estimate maximal post-synaptic GluR response. Mutant glutamate-evoked current amplitudes were normalized to control response amplitudes under the same application conditions to allow comparison of all experiments (Fig. 4D). Post-synaptic currents were filtered (1-2 kHz) and acquired to disk (5-kHz sampling) using Axon Instrument hardware and computer interface, and analyzed with PClamp versions 6-8 software. Representative data traces were exported and prepared for display using Igor or standard spreadsheet and graphics software.

\section{Electron microscopy and immuno-EM}

Mutant $\left[\mathrm{mtg}^{1} / \mathrm{mtg}^{1}\right.$ and $\left.m \mathrm{tg}^{1} / \mathrm{Df}(\mathrm{CA3})\right]$ and wild-type control embryos were collected at 21-22 $\mathrm{h}$ from timed egg lays and fixed, sectioned, and visualized in parallel using standard TEM techniques, as reported previously (Featherstone et al. 2001). Briefly, embryos were dechorionated with bleach and removed from the vitelline membrane, and the anterior and posterior ends were excised in $5 \%$ glutaraldehyde in $0.08 \mathrm{M}$ phosphate buffer. Embryos were transferred to $2.5 \%$ glutaraldeyde in 0.08 $\mathrm{M}$ phosphate-buffered sucrose for $1 \mathrm{~h}$, washed three times in PBS, transferred to $1 \% \mathrm{OsO}_{4}$ in $\mathrm{dH}_{2} \mathrm{O}$ for $1 \mathrm{~h}$, and washed three times in $\mathrm{dH}_{2} \mathrm{O}$. Preparations were then stained en bloc in $1 \%$ aqueous uranyl acetate for $1 \mathrm{~h}$, washed three times in $\mathrm{dH}_{2} \mathrm{O}$, dehydrated in an ethanol series $(30 \%-100 \%)$, passed through propylene oxide, transferred to a 1:1 araldite:propylene oxide mixture, and removed and embedded in araldite embedding media. Ultrathin serial sections $(50-60 \mathrm{~nm})$ were obtained on a Leica UCT Ultracut microtome and transferred to formvarcoated grids. Grids were examined and images were collected on a Phillips CM10 TEM equipped with an AMT 2-megapixel camera. NMJs were serially sectioned, and profiles for each identified synaptic bouton were quantified in the section containing the most prominent electron-dense AZ and T-bar structures. Only sections containing a single AZ were quantified. Synaptic vesicles in the "clustered" pool were defined as those within $250 \mathrm{~nm}$ of the AZ. Docked vesicles were defined as those within 0.5 vesicle diameter $(<20 \mathrm{~nm})$ of the electron-dense AZ plasma membrane. Measurements and quantification were made using ImageJ software. Bouton and mitochondria area; number of docked, clustered, and total vesicles; and vesicle density (corrected for mitochondria area) were scored for each profile. Synaptic cleft density was qualitatively scored in the principal AZcontaining section, as well as in one to two adjacent serial sections. Post-synaptic comparison was based on high-magnificaion scoring of polyribosomes within the region directly postsynaptic to the AZ. Mean quantified parameters were statistically compared using the Mann-Whitney test, and presentation images were processed in Adobe Photoshop.

Immuno-EM of wild-type third instar larvae was performed by adapting published methods (Usuda et al. 1990; McDonald 1999; Sharp et al. 1999). Dissected larvae were fixed for $2 \mathrm{~h}$ in $4 \%$ paraformaldehyde plus $0.5 \%$ glutaraldehyde, rinsed in PBS 
for $6 \mathrm{~min}$, and passed through an ethanol series $150 \%, 70 \%$, $100 \%$; 20 min each). Propylene oxide:araldite (1:1) was used as a transition media to $100 \%$ araldite. Tissue was placed in a flat embedding mold and cured overnight in a $60^{\circ} \mathrm{C}$ oven. Gold thin sections were obtained from Leica UCT Ultracut microtome, using 200-mesh nickel grids on which to collect sections. Grids were blocked for 15 min with 1\% BSA in DPBS (Dulbecco's), and incubated overnight at $4{ }^{\circ} \mathrm{C}$ in MTG rabbit primary antibody (sera $1 \mathrm{~A}, 1 \mathrm{~B}, 2 \mathrm{~A}$, or $2 \mathrm{~B} ; 1 / 500$ dilution in DPBS $+1 \% \mathrm{BSA}$ ). Grids were washed for $1 \mathrm{~h}$ in DPBS with Tween-20, and for $15 \mathrm{~min}$ in TRIS buffer with $0.05 \%$ Tween-20, blocked for 15 min with $1 \%$ BSA in TRIS buffer, and incubated for $1 \mathrm{~h}$ at room temperature in secondary antibody conjugated to 10 - or $25-\mathrm{nm}$ gold particles (1/25 dilution, Aurion). Grids were washed for $15 \mathrm{~min}$ in TRIS buffer $+0.05 \%$ Tween-20, washed again for $15 \mathrm{~min}$ in $\mathrm{dH}_{2} \mathrm{O}$, and blotted dry. Sections were stained with uranyl acetate and lead citrate, and examined and imaged as for TEM. Grain scoring and grain density measurements were quantified in ImageJ by outlining the areas of the presynaptic bouton, post-synaptic SSR, and surrounding nonsynaptic muscle tissue in each profile. AZ localized grains were defined as those within a $250-\mathrm{nm}$ radius half-circular area $\left(0.098 \mu^{2}\right)$ centered on the AZ synaptic cleft, and included both extracellular and presynaptic grains. Background grain counts and density measurements were made in preparations incubated in immunogold as above $(1 / 25$ dilution), without exposure to anti-MTG primary antibody.

\section{Acknowledgments}

We are particularly grateful to the following for essential antibodies: Hugo Bellen (Syt), Graeme Davis (Dock), Linda Ballard (dPak), Brian McCabe (dPix), Aaron DiAntonio (GluRIIC), and Stephan Sigrist (GluRIID). We gratefully acknowledge the Bloomington Drosophila Stock Center and the Iowa Hybridoma Bank for essential genetic and antibody reagents. We thank Stephanie Miller, Ariana Beck, and Meeta Wagle for technical assistance. This work supported by NIH grant GM54544 to K.B.

\section{References}

Albin, S.D. and Davis, G.W. 2004. Coordinating structural and functional synapse development: Postsynaptic p21-activated kinase independently specifies glutamate receptor abundance and postsynaptic morphology. I. Neurosci. 24: 68716879.

Ang, L.H., Kim, J., Stepensky, V., and Hing, H. 2003. Dock and Pak regulate olfactory axon pathfinding in Drosophila. Development 130: 1307-1316.

Ashley, J., Packard, M., Ataman, B., and Budnik, V. 2005. Fasciclin II signals new synapse formation through amyloid precursor protein and the scaffolding protein $\mathrm{dX11/Mint.} J$. Neurosci. 25: 5943-5955.

Ataman, B., Ashley, J., Gorczyca, D., Gorczyca, M., Mathew, D., Wichmann, C., Sigrist, S.J., and Budnik, V. 2006. Nuclear trafficking of Drosophila Frizzled-2 during synapse development requires the PDZ protein dGRIP. Proc. Nat1. Acad. Sci. 103: 7841-7846.

Bahr, B.A. 2000. Integrin-type signaling has a distinct influence on NMDA-induced cytoskeletal disassembly. J. Neurosci. Res. 59: 827-832.

Bahr, B.A., Staubli, U., Xiao, P., Chun, D., Ji, Z.X., Esteban, E.T., and Lynch, G. 1997. Arg-Gly-Asp-Ser-selective adhesion and the stabilization of long-term potentiation: Pharmacological studies and the characterization of a candidate matrix receptor. J. Neurosci. 17: 1320-1329.

Baines, R.A., Robinson, S.G., Fujioka, M., Jaynes, J.B., and Bate, M. 1999. Postsynaptic expression of tetanus toxin light chain blocks synaptogenesis in Drosophila. Curr. Biol. 9: 1267-1270.

Baines, R.A., Uhler, J.P., Thompson, A., Sweeney, S.T., and Bate, M. 2001. Altered electrical properties in Drosophila neurons developing without synaptic transmission. I. Neurosci. 21: 1523-1531.

Benton, R. 2006. On the ORigin of smell: Odorant receptors in insects. Cell. Mol. Life Sci. 63: 1579-1585.

Bernard-Trifilo, J.A., Kramar, E.A., Torp, R., Lin, C.Y., Pineda, E.A., Lynch, G., and Gall, C.M. 2005. Integrin signaling cascades are operational in adult hippocampal synapses and modulate NMDA receptor physiology. J. Neurochem. 93: 834-849.

Beumer, K.J., Rohrbough, J., Prokop, A., and Broadie, K. 1999. A role for PS integrins in morphological growth and synaptic function at the postembryonic neuromuscular junction of Drosophila. Development 126: 5833-5846.

Beumer, K., Matthies, H.J., Bradshaw, A., and Broadie, K. 2002. Integrins regulate DLG/FAS2 via a CaM kinase II-dependent pathway to mediate synapse elaboration and stabilization during postembryonic development. Development 129: 3381-3391.

Bezakova, G. and Ruegg, M.A. 2003. New insights into the roles of agrin. Nat. Rev. Mol. Cell Biol. 4: 295-308.

Biederer, T., Sara, Y., Mozhayeva, M., Atasoy, D., Liu, X., Kavalali, E.T., and Sudhof, T.C. 2002. SynCAM, a synaptic adhesion molecule that drives synapse assembly. Science 297: 1525-1531.

Boraston, A.B., Bolam, D.N., Gilbert, H.J., and Davies, G.J. 2004. Carbohydrate-binding modules: Fine-tuning polysaccharide recognition. Biochem. J. 382: 769-781.

Broadie, K. and Bate, M. 1993a. Activity-dependent development of the neuromuscular synapse during Drosophila embryogenesis. Neuron 11: 607-619.

Broadie, K. and Bate, M. 1993b. Innervation directs receptor synthesis and localization in Drosophila embryo synaptogenesis. Nature 361: 350-353.

Broadie, K.S. and Bate, M. 1993c. Development of the embryonic neuromuscular synapse of Drosophila melanogaster. J. Neurosci. 13: 144-166.

Bruckner, K., Pablo Labrador, J., Scheiffele, P., Herb, A., Seeburg, P.H., and Klein, R. 1999. EphrinB ligands recruit GRIP family PDZ adaptor proteins into raft membrane microdomains. Neuron 22: 511-524.

Bunch, T.A., Grinblat, Y., and Goldstein, L.S. 1988. Characterization and use of the Drosophila metallothionein promoter in cultured Drosophila melanogaster cells. Nucleic Acids Res. 16: 1043-1061.

Chan, C.S., Weeber, E.J., Kurup, S., Sweatt, J.D., and Davis, R.L. 2003. Integrin requirement for hippocampal synaptic plasticity and spatial memory. J. Neurosci. 23: 7107-7116.

Chan, C.S., Weeber, E.J., Zong, L., Fuchs, E., Sweatt, J.D., and Davis, R.L. 2006. $\beta$ 1-integrins are required for hippocampal AMPA receptor-dependent synaptic transmission, synaptic plasticity, and working memory. J. Neurosci. 26: 223-232.

Chavis, P. and Westbrook, G. 2001. Integrins mediate functional pre- and postsynaptic maturation at a hippocampal synapse. Nature 411: 317-321.

Chen, K. and Featherstone, D.E. 2005. Discs-large (DLG) is clustered by presynaptic innervation and regulates postsynaptic glutamate receptor subunit composition in Drosophila. BMC Biol. 3: 1. doi: 10.1186/1741-7007-3-1.

Chen, K., Merino, C., Sigrist, S.J., and Featherstone, D.E. 2005. 
The 4.1 protein coracle mediates subunit-selective anchoring of Drosophila glutamate receptors to the postsynaptic actin cytoskeleton. J. Neurosci. 25: 6667-6675.

Chih, B., Engelman, H., and Scheiffele, P. 2005. Control of excitatory and inhibitory synapse formation by neuroligins. Science 307: 1324-1328.

Dalva, M.B., Takasu, M.A., Lin, M.Z., Shamah, S.M., Hu, L., Gale, N.W., and Greenberg, M.E. 2000. EphB receptors interact with NMDA receptors and regulate excitatory synapse formation. Cell 103: 945-956.

Davoli, C., Marconi, A., Serafino, A., Iannoni, C., Marcheggiano, A., and Ravagnan, G. 2002. Expression of nerve growth factor-like polypeptides and immunoreactivity related to the two types of neurotrophin receptors in earthworm tissues. Cell. Mol. Life Sci. 59: 527-539.

Deak, P., Omar, M.M., Saunders, R.D., Pal, M., Komonyi, O., Szidonya, J., Maroy, P., Zhang, Y., Ashburner, M., Benos, P., et al. 1997. P-element insertion alleles of essential genes on the third chromosome of Drosophila melanogaster: Correlation of physical and cytogenetic maps in chromosomal region 86E-87F. Genetics 147: 1697-1722.

Dean, C., Scholl, F.G., Choih, J., DeMaria, S., Berger, J., Isacoff, E., and Scheiffele, P. 2003. Neurexin mediates the assembly of presynaptic terminals. Nat. Neurosci. 6: 708-716.

Dekkers, L.C., van der Plas, M.C., van Loenen, P.B., den Dunnen, J.T., van Ommen, G.J., Fradkin, L.G., and Noordermeer, J.N. 2004. Embryonic expression patterns of the Drosophila dystrophin-associated glycoprotein complex orthologs. Brain Res. Gene Expr. Patterns 4: 153-159.

Desnoyers, L. 2004. Structural basis and therapeutic implication of the interaction of CCN proteins with glycoconjugates. Curr. Pharm. Des. 10: 3913-3928.

DiAntonio, A. 2006. Glutamate receptors at the Drosophila neuromuscular junction. Int. Rev. Neurobiol. 75: 165-179.

DiAntonio, A., Petersen, S.A., Heckmann, M., and Goodman, C.S. 1999. Glutamate receptor expression regulates quantal size and quantal content at the Drosophila neuromuscular junction. J. Neurosci. 19: 3023-3032.

Dityatev, A. and Schachner, M. 2003. Extracellular matrix molecules and synaptic plasticity. Nat. Rev. Neurosci. 4: 456468.

Dityatev, A. and Schachner, M. 2006. The extracellular matrix and synapses. Cell Tissue Res. 326: 647-654.

Dityatev, A., Frischknecht, R., and Seidenbecher, C.I. 2006. Extracellular matrix and synaptic functions. Results Probl. Cell Differ. 43: 69-97.

Ethell, I.M. and Pasquale, E.B. 2005. Molecular mechanisms of dendritic spine development and remodeling. Prog. Neurobiol. 75: 161-205.

Ethell, I.M. and Yamaguchi, Y. 1999. Cell surface heparan sulfate proteoglycan syndecan-2 induces the maturation of dendritic spines in rat hippocampal neurons. J. Cell Biol. 144: 575-586.

Ethell, I.M., Irie, F., Kalo, M.S., Couchman, J.R., Pasquale, E.B., and Yamaguchi, Y. 2001. EphB/syndecan-2 signaling in dendritic spine morphogenesis. Neuron 31: 1001-1013.

Featherstone, D.E., Rushton, E.M., Hilderbrand-Chae, M., Phillips, A.M., Jackson, F.R., and Broadie, K. 2000. Presynaptic glutamic acid decarboxylase is required for induction of the postsynaptic receptor field at a glutamatergic synapse. Neuron 27: 71-84.

Featherstone, D.E., Davis, W.S., Dubreuil, R.R., and Broadie, K. 2001. Drosophila $\alpha$ - and $\beta$-spectrin mutations disrupt presynaptic neurotransmitter release. I. Neurosci. 21: 42154224.

Featherstone, D.E., Rushton, E., and Broadie, K. 2002. Develop- mental regulation of glutamate receptor field size by nonvesicular glutamate release. Nat. Neurosci. 5: 141-146.

Featherstone, D.E., Rushton, E., Rohrbough, J., Liebl, F., Karr, J., Sheng, Q., Rodesch, C.K., and Broadie, K. 2005. An essential Drosophila glutamate receptor subunit that functions in both central neuropil and neuromuscular junction. I. Neurosci. 25: 3199-3208.

Fox, A.N. and Zinn, K. 2005. The heparan sulfate proteoglycan syndecan is an in vivo ligand for the Drosophila LAR receptor tyrosine phosphatase. Curr. Biol. 15: 1701-1711.

Gorczyca, D., Ashley, J., Speese, S., Gherbesi, N., Thomas, U., Gundelfinger, E., Gramates, L.S., and Budnik, V. 2007. Postsynaptic membrane addition depends on the Discs-Largeinteracting t-SNARE Gtaxin. J. Neurosci. 27: 1033-1044.

Grady, R.M., Zhou, H., Cunningham, J.M., Henry, M.D., Campbell, K.P., and Sanes, J.R. 2000. Maturation and maintenance of the neuromuscular synapse: Genetic evidence for roles of the dystrophin-glycoprotein complex. Neuron 25: 279-293.

Graf, E.R., Zhang, X., Jin, S.X., Linhoff, M.W., and Craig, A.M. 2004. Neurexins induce differentiation of GABA and glutamate postsynaptic specializations via neuroligins. Cell 119: 1013-1026.

Grumbling, G. and Strelets, V. 2006. FlyBase: Anatomical data, images and queries. Nucleic Acids Res. 34: 484-488.

Haines, N. and Stewart, B.A. 2007. Functional roles for $\beta 1,4-N$ acetlygalactosaminyltransferase-A in Drosophila larval neurons and muscles. Genetics 175: 671-679.

Hakeda-Suzuki, S., Ng, J., Tzu, J., Dietzl, G., Sun, Y., Harms, M., Nardine, T., Luo, L., and Dickson, B.J. 2002. Rac function and regulation during Drosophila development. Nature 416: 438-442.

Hall, A.C., Lucas, F.R., and Salinas, P.C. 2000. Axonal remodeling and synaptic differentiation in the cerebellum is regulated by WNT-7a signaling. Cell 100: 525-535.

Harden, N., Lee, J., Loh, H.Y., Ong, Y.M., Tan, I., Leung, T., Manser, E., and Lim, L. 1996. A Drosophila homolog of the Rac- and Cdc42-activated serine/threonine kinase PAK is a potential focal adhesion and focal complex protein that colocalizes with dynamic actin structures. Mol. Cell. Biol. 16: 1896-1908.

Hearn, M.T. and Gomme, P.T. 2000. Molecular architecture and biorecognition processes of the cystine knot protein superfamily: Part I. The glycoprotein hormones. J. Mol. Recognit. 13: 223-278.

Henry, M.D. and Campbell, K.P. 1996. Dystroglycan: An extracellular matrix receptor linked to the cytoskeleton. Curr. Opin. Cell Biol. 8: 625-631.

Hoshino, M., Suzuki, E., Nabeshima, Y., and Hama, C. 1996. Hikaru genki protein is secreted into synaptic clefts from an early stage of synapse formation in Drosophila. Development 122: 589-597.

Hoshino, M., Suzuki, E., Miyake, T., Sone, M., Komatsu, A. Nabeshima, Y., and Hama, C. 1999. Neural expression of hikaru genki protein during embryonic and larval development of Drosophila melanogaster. Dev. Genes Evol. 209: $1-9$.

Huang, F.D., Woodruff, E., Mohrmann, R., and Broadie, K. 2006. Rolling blackout is required for synaptic vesicle exocytosis. I. Neurosci. 26: 2369-2379.

Johnson, K.G., Tenney, A.P., Ghose, A., Duckworth, A.M., Higashi, M.E., Parfitt, K., Marcu, O., Heslip, T.R., Marsh, J.L., Schwarz, T.L., et al. 2006. The HSPGs Syndecan and Dallylike bind the receptor phosphatase LAR and exert distinct effects on synaptic development. Neuron 49: 517-531.

Kim, E. and Sheng, M. 2004. PDZ domain proteins of synapses. Nat. Rev. Neurosci. 5: 771-781. 
Kitamura, N., Ikekita, M., Sato, T., Akimoto, Y., Hatanaka, Y., Kawakami, H., Inomata, M., and Furukawa, K. 2005. Mouse $\mathrm{Na}^{+} / \mathrm{K}^{+}$-ATPase $\beta 1$-subunit has a $\mathrm{K}^{+}$-dependent cell adhesion activity for $\beta$-GlcNAc-terminating glycans. Proc. Natl. Acad. Sci. 102: 2796-2801.

Kramar, E.A., Bernard, J.A., Gall, C.M., and Lynch, G. 2003. Integrins modulate fast excitatory transmission at hippocampal synapses. J. Biol. Chem. 278: 10722-10730.

Kramar, E.A., Lin, B., Rex, C.S., Gall, C.M., and Lynch, G. 2006. Integrin-driven actin polymerization consolidates long-term potentiation. Proc. Natl. Acad. Sci. 103: 5579-5584.

Kummer, T.T., Misgeld, T., Lichtman, J.W., and Sanes, J.R. 2004. Nerve-independent formation of a topologically complex postsynaptic apparatus. J. Cell Biol. 164: 1077-1087.

Kummer, T.T., Misgeld, T., and Sanes, J.R. 2006. Assembly of the postsynaptic membrane at the neuromuscular junction: Paradigm lost. Curr. Opin. Neurobiol. 16: 74-82.

Lahey, T., Gorczyca, M., Jia, X.X., and Budnik, V. 1994. The Drosophila tumor suppressor gene dlg is required for normal synaptic bouton structure. Neuron 13: 823-835.

Levinson, J.N., Chery, N., Huang, K., Wong, T.P., Gerrow, K., Kang, R., Prange, O., Wang, Y.T., and El-Husseini, A. 2005. Neuroligins mediate excitatory and inhibitory synapse formation: Involvement of PSD-95 and neurexin-1 $\beta$ in neuroligin-induced synaptic specificity. J. Biol. Chem. 280: 1731217319.

Lin, B., Arai, A.C., Lynch, G., and Gall, C.M. 2003. Integrins regulate NMDA receptor-mediated synaptic currents. I. Neurophysiol. 89: 2874-2878.

Malenka, R.C. and Bear, M.F. 2004. LTP and LTD: An embarrassment of riches. Neuron 44: 5-21.

Marques, G. 2005. Morphogens and synaptogenesis in Drosophila. J. Neurobiol. 64: 417-434.

Marrus, S.B. and DiAntonio, A. 2004. Preferential localization of glutamate receptors opposite sites of high presynaptic release. Curr. Biol. 14: 924-931.

Marrus, S.B., Portman, S.L., Allen, M.J., Moffat, K.G., and DiAntonio, A. 2004. Differential localization of glutamate receptor subunits at the Drosophila neuromuscular junction. I. Neurosci. 24: 1406-1415.

Martin, P.T. 2002. Glycobiology of the synapse. Glycobiology 12: $1 \mathrm{R}-7 \mathrm{R}$.

Martin, P.T. 2003a. Dystroglycan glycosylation and its role in matrix binding in skeletal muscle. Glycobiology 13: 55R66R. doi: 10.1093/glycob/cwg076.

Martin, P.T. 2003b. Glycobiology of the neuromuscular junction. J. Neurocytol. 32: 915-929.

Mathew, D., Ataman, B., Chen, J., Zhang, Y., Cumberledge, S., and Budnik, V. 2005. Wingless signaling at synapses is through cleavage and nuclear import of receptor DFrizzled2. Science 310: 1344-1347.

Matsunami, H. and Amrein, H. 2003. Taste and pheromone perception in mammals and flies. Genome Biol. 4: 220. doi: 10.1186/gb-2003-4-7-220.

McDonald, K. 1999. High-pressure freezing for preservation of high resolution fine structure and antigenicity for immunolabeling. Methods Mol. Biol. 117: 77-97.

McDonald, N.Q. and Hendrickson, W.A. 1993. A structural superfamily of growth factors containing a cystine knot motif. Cell 73: 421-424.

Mentzel, B. and Raabe, T. 2005. Phylogenetic and structural analysis of the Drosophila melanogaster p21-activated kinase DmPAK3. Gene 349: 25-33.

Mi, R., Tang, X., Sutter, R., Xu, D., Worley, P., and O'Brien, R.J. 2002. Differing mechanisms for glutamate receptor aggregation on dendritic spines and shafts in cultured hippocampal neurons. J. Neurosci. 22: 7606-7616.

Mi, R., Sia, G.M., Rosen, K., Tang, X., Moghekar, A., Black, J.L., McEnery, M., Huganir, R.L., and O'Brien, R.J. 2004. AMPA receptor-dependent clustering of synaptic NMDA receptors is mediated by Stargazin and NR2A/B in spinal neurons and hippocampal interneurons. Neuron 44: 335-349.

Misgeld, T., Kummer, T.T., Lichtman, J.W., and Sanes, J.R. 2005. Agrin promotes synaptic differentiation by counteracting an inhibitory effect of neurotransmitter. Proc. Natl. Acad. Sci. 102: 11088-11093.

Nam, C.I. and Chen, L. 2005. Postsynaptic assembly induced by neurexin-neuroligin interaction and neurotransmitter. Proc. Natl. Acad. Sci. 102: 6137-6142.

Newsome, T.P., Schmidt, S., Dietzl, G., Keleman, K., Asling, B., Debant, A., and Dickson, B.J. 2000. Trio combines with dock to regulate Pak activity during photoreceptor axon pathfinding in Drosophila. Cell 101: 283-294.

Nishimune, H., Sanes, J.R., and Carlson, S.S. 2004. A synaptic laminin-calcium channel interaction organizes active zones in motor nerve terminals. Nature 432: 580-587.

O'Brien, R.J., Xu, D., Petralia, R.S., Steward, O., Huganir, R.L., and Worley, P. 1999. Synaptic clustering of AMPA receptors by the extracellular immediate-early gene product Narp. Neuron 23: 309-323.

O'Brien, R., Xu, D., Mi, R., Tang, X., Hopf, C., and Worley, P. 2002. Synaptically targeted narp plays an essential role in the aggregation of AMPA receptors at excitatory synapses in cultured spinal neurons. J. Neurosci. 22: 4487-4498.

Ohtsuka, A., Taguchi, T., Sayed, R., and Murakami, T. 2000. The spatial relationship between the perineuronal proteoglycan network and the synaptic boutons as visualized by double staining with cationic colloidal iron method and anticalbindin-D-28K immunohistochemistry in rat cerebellar nuclei. Arch. Histol. Cytol. 63: 313-318.

Packard, M., Koo, E.S., Gorczyca, M., Sharpe, J., Cumberledge, S., and Budnik, V. 2002. The Drosophila Wnt, wingless, provides an essential signal for pre- and postsynaptic differentiation. Cell 111: 319-330.

Parnas, D., Haghighi, A.P., Fetter, R.D., Kim, S.W., and Goodman, C.S. 2001. Regulation of postsynaptic structure and protein localization by the Rho-type guanine nucleotide exchange factor dPix. Neuron 32: 415-424.

Perez-Otano, I. and Ehlers, M.D. 2005. Homeostatic plasticity and NMDA receptor trafficking. Trends Neurosci. 28: 229238.

Petersen, S.A., Fetter, R.D., Noordermeer, J.N., Goodman, C.S., and DiAntonio, A. 1997. Genetic analysis of glutamate receptors in Drosophila reveals a retrograde signal regulating presynaptic transmitter release. Neuron 19: 1237-1248.

Prokop, A. 1999. Integrating bits and pieces: Synapse structure and formation in Drosophila embryos. Cell Tissue Res. 297: 169-186.

Prokop, A., Martin-Bermudo, M.D., Bate, M., and Brown, N.H. 1998. Absence of PS integrins or laminin A affects extracellular adhesion, but not intracellular assembly, of hemiadherens and neuromuscular junctions in Drosophila embryos. Dev. Biol. 196: 58-76.

Qin, G., Schwarz, T., Kittel, R.J., Schmid, A., Rasse, T.M., Kappei, D., Ponimaskin, E., Heckmann, M., and Sigrist, S.J. 2005. Four different subunits are essential for expressing the synaptic glutamate receptor at neuromuscular junctions of Drosophila. J. Neurosci. 25: 3209-3218.

Rao, Y. 2005. Dissecting Nck/Dock signaling pathways in Drosophila visual system. Int. J. Biol. Sci. 1: 80-86.

Rao, Y. and Zipursky, S.L. 1998. Domain requirements for the Dock adapter protein in growth-cone signaling. Proc. Natl. 
Acad. Sci. 95: 2077-2082.

Rasse, T.M., Fouquet, W., Schmid, A., Kittel, R.J., Mertel, S., Sigrist, C.B., Schmidt, M., Guzman, A., Merino, C., Qin, G., et al. 2005. Glutamate receptor dynamics organizing synapse formation in vivo. Nat. Neurosci. 8: 898-905.

Rohrbough, J., Grotewiel, M.S., Davis, R.L., and Broadie, K. 2000. Integrin-mediated regulation of synaptic morphology, transmission, and plasticity. J. Neurosci. 20: 6868-6878.

Rohrbough, J., Rushton, E., Palanker, L., Woodruff, E., Matthies, H.J., Acharya, U., Acharya, J.K., and Broadie, K. 2004. Ceramidase regulates synaptic vesicle exocytosis and trafficking. J. Neurosci. 24: 7789-7803.

Saitoe, M., Tanaka, S., Takata, K., and Kidokoro, Y. 1997. Neural activity affects distribution of glutamate receptors during neuromuscular junction formation in Drosophila embryos. Dev. Biol. 184: 48-60.

Saitoe, M., Schwarz, T.L., Umbach, J.A., Gundersen, C.B., and Kidokoro, Y. 2001. Absence of junctional glutamate receptor clusters in Drosophila mutants lacking spontaneous transmitter release. Science 293: 514-517.

Salinas, P.C. 2003. Synaptogenesis: Wnt and TGF- $\beta$ take centre stage. Curr. Biol. 13: R60-R62. doi: 10.1016/S09609822(02)01429-X.

Sanes, J.R. and Lichtman, J.W. 2001. Induction, assembly, maturation and maintenance of a postsynaptic apparatus. Nat. Rev. Neurosci. 2: 791-805.

Sara, Y., Biederer, T., Atasoy, D., Chubykin, A., Mozhayeva, M.G., Sudhof, T.C., and Kavalali, E.T. 2005. Selective capability of SynCAM and neuroligin for functional synapse assembly. J. Neurosci. 25: 260-270.

Scheiffele, P. 2003. Cell-cell signaling during synapse formation in the CNS. Annu. Rev. Neurosci. 26: 485-508.

Scheiffele, P., Fan, J., Choih, J., Fetter, R., and Serafini, T. 2000. Neuroligin expressed in nonneuronal cells triggers presynaptic development in contacting axons. Cell 101: 657-669.

Sharp, D.J., McDonald, K.L., Brown, H.M., Matthies, H.J., Walczak, C., Vale, R.D., Mitchison, T.J., and Scholey, J.M. 1999. The bipolar kinesin, KLP61F, cross-links microtubules within interpolar microtubule bundles of Drosophila embryonic mitotic spindles. J. Cell Biol. 144: 125-138.

Shi, Y. and Ethell, I.M. 2006. Integrins control dendritic spine plasticity in hippocampal neurons through NMDA receptor and $\mathrm{Ca}^{2+} /$ calmodulin-dependent protein kinase II-mediated actin reorganization. J. Neurosci. 26: 1813-1822.

Sigrist, S.J., Thiel, P.R., Reiff, D.F., Lachance, P.E., Lasko, P., and Schuster, C.M. 2000. Postsynaptic translation affects the efficacy and morphology of neuromuscular junctions. Nature 405: 1062-1065.

Sigrist, S.J., Reiff, D.F., Thiel, P.R., Steinert, J.R., and Schuster, C.M. 2003. Experience-dependent strengthening of Drosophila neuromuscular junctions. I. Neurosci. 23: 65466556.

Sone, M., Hoshino, M., Suzuki, E., Kuroda, S., Kaibuchi, K., Nakagoshi, H., Saigo, K., Nabeshima, Y., and Hama, C. 1997. Still life, a protein in synaptic terminals of Drosophila homologous to GDP-GTP exchangers. Science 275: 543-547.

Staubli, U., Chun, D., and Lynch, G. 1998. Time-dependent reversal of long-term potentiation by an integrin antagonist. J. Neurosci. 18: 3460-3469.

Sun, P.D. and Davies, D.R. 1995. The cystine-knot growth-factor superfamily. Annu. Rev. Biophys. Biomol. Struct. 24: 269-291.

Umemori, H., Linhoff, M.W., Ornitz, D.M., and Sanes, J.R. 2004. FGF22 and its close relatives are presynaptic organizing molecules in the mammalian brain. Cell 118: 257-270.

Usuda, N., Ma, H.J., Hanai, T., Yokota, S., Hashimoto, T., and
Nagata, T. 1990. Immunoelectron microscopy of tissues processed by rapid freezing and freeze-substitution fixation without chemical fixatives: Application to catalase in rat liver hepatocytes. J. Histochem. Cytochem. 38: 617-623.

van der Plas, M.C., Pilgram, G.S., Plomp, J.J., de Jong, A., Fradkin, L.G., and Noordermeer, J.N. 2006. Dystrophin is required for appropriate retrograde control of neurotransmitter release at the Drosophila neuromuscular junction. J. Neurosci. 26: 333-344.

van Kesteren, R.E., Fainzilber, M., Hauser, G., van Minnen, J., Vreugdenhil, E., Smit, A.B., Ibanez, C.F., Geraerts, W.P., and Bulloch, A.G. 1998. Early evolutionary origin of the neurotrophin receptor family. EMBO J. 17: 2534-2542.

Viapiano, M.S. and Matthews, R.T. 2006. From barriers to bridges: Chondroitin sulfate proteoglycans in neuropathology. Trends Mol. Med. 12: 488-496.

Vitt, U.A., Hsu, S.Y., and Hsueh, A.J. 2001. Evolution and classification of cystine knot-containing hormones and related extracellular signaling molecules. Mol. Endocrinol. 15: 681694.

Webb, D.J., Kovalenko, M., Whitmore, L., and Horwitz, A.F. 2006. Phosphorylation of serine 709 in GIT1 regulates protrusive activity in cells. Biochem. Biophys. Res. Commun. 346: 1284-1288.

Webb, D.J., Zhang, H., Majumdar, D., and Horwitz, A.F. 2007. $\alpha 5$ Integrin signaling regulates the formation of spines and synapses in hippocampal neurons. J. Biol. Chem. 282: 69296935.

Werner, L.A. and Manseau, L.J. 1997. A Drosophila gene with predicted rhoGEF, pleckstrin homology and SH3 domains is highly expressed in morphogenic tissues. Gene 187: 107114.

Wilson, C., Goberdhan, D.C., and Steller, H. 1993. Dror, a potential neurotrophic receptor gene, encodes a Drosophila homolog of the vertebrate Ror family of Trk-related receptor tyrosine kinases. Proc. Natl. Acad. Sci. 90: 7109-7113.

Yamaguchi, Y. 2000. Lecticans: Organizers of the brain extracellular matrix. Cell. Mol. Life Sci. 57: 276-289.

Yuan, L.L. and Ganetzky, B. 1999. Searching for molecules mediating glial-neuronal communication. Mol. Psychiatry 4: 408-409.

Zhang, H., Webb, D.J., Asmussen, H., and Horwitz, A.F. 2003. Synapse formation is regulated by the signaling adaptor GIT1. J. Cell Biol. 161: 131-142.

Zhang, H., Webb, D.J., Asmussen, H., Niu, S., and Horwitz, A.F. 2005. A GIT1/PIX/Rac/PAK signaling module regulates spine morphogenesis and synapse formation through MLC. I. Neurosci. 25: 3379-3388. 


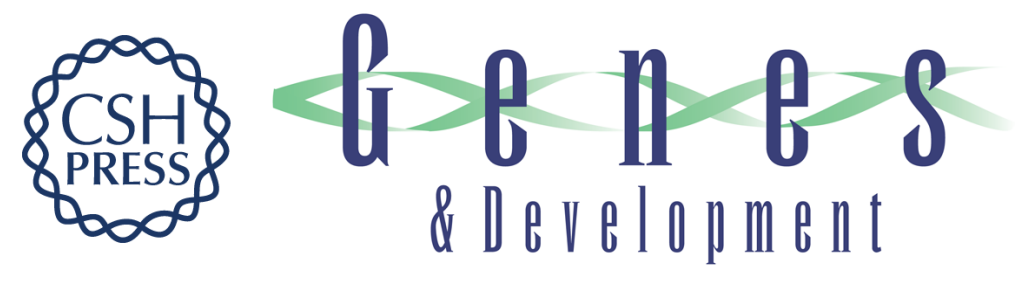

\section{Presynaptic establishment of the synaptic cleft extracellular matrix is required for post-synaptic differentiation}

Jeffrey Rohrbough, Emma Rushton, Elvin Woodruff III, et al.

Genes Dev. 2007, 21: originally published online September 27, 2007

Access the most recent version at doi:10.1101/gad.1574107

\section{Supplemental http://genesdev.cshlp.org/content/suppl/2007/10/02/gad.1574107.DC1 \\ Material}

References This article cites 129 articles, 50 of which can be accessed free at:

http://genesdev.cshlp.org/content/21/20/2607.full.html\#ref-list-1

License

Email Alerting

Receive free email alerts when new articles cite this article - sign up in the box at the top

Service

right corner of the article or click here.

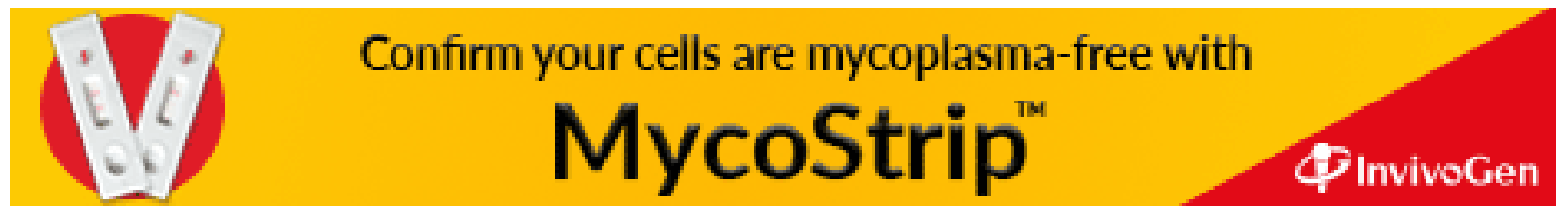

